\title{
Biologic Treatment Algorithms for Moderate-to-Severe Psoriasis with Comorbid Conditions and Special Populations: A Review
}

\author{
Akshitha Thatiparthi ${ }^{1} \cdot$ Amylee Martin $^{2} \cdot$ Jeffrey Liu $^{3} \cdot$ Alexander Egeberg ${ }^{4} \cdot$ Jashin J. Wu $^{5}$ (D)
}

Accepted: 27 March 2021 / Published online: 16 April 2021

(c) The Author(s), under exclusive licence to Springer Nature Switzerland AG 2021

\begin{abstract}
The emergence of data from clinical trials of biologics, the approval of new biologics, and our improved understanding of psoriasis pathogenesis have increased the therapeutic possibilities for the treatment of moderate-to-severe psoriasis. Biologics currently approved for the treatment of psoriasis include tumor necrosis factor inhibitors, interleukin (IL)-17 inhibitors, ustekinumab (an IL-12/23 inhibitor), and IL-23 inhibitors. Data from clinical trials and studies of the safety and efficacy of biologics provide essential information for the personalization of patient care. We discuss the benefits and disadvantages of biologics as a first-line treatment choice, update treatment recommendations according to current evidence, and propose psoriasis treatment algorithms. Our discussion includes the following comorbid conditions: psoriatic arthritis, multiple sclerosis, congestive heart failure, inflammatory bowel disease, hepatitis B, nonmelanoma skin cancer, lymphoma, and latent tuberculosis. We make evidence-based treatment recommendations for special populations, including pediatric patients, patients with coronavirus 2019 (COVID-19), and pregnant and breastfeeding patients with psoriasis. Ultimately, individualized recommendations that consider patient preferences, disease severity, comorbid conditions, and additional risk factors should be offered to patients and updated as new trial data emerges.
\end{abstract}

\section{Introduction}

Psoriasis is a chronic condition with several systemic and immune manifestations that affects more than 125 million people worldwide [1-3]. Studies have shown associations between psoriasis and other conditions, including psoriatic arthritis (PsA), multiple sclerosis (MS), congestive heart failure (CHF), inflammatory bowel disease (IBD), malignancy, and mood disorders [2, 4, 5]. Several effective psoriasis treatments have emerged within the last decade [6]. Approved biologics for the treatment of moderate-to-severe

Jashin J. Wu

jashinwu@hotmail.com

1 College of Osteopathic Medicine of the Pacific, Western University of Health Sciences, Pomona, CA, USA

2 School of Medicine, University of California, Riverside, CA, USA

3 Keck School of Medicine, University of Southern California, Los Angeles, CA, USA

4 Department of Dermatology, Bispebjerg University Hospital, University of Copenhagen, Copenhagen, NV, Denmark

5 Dermatology Research and Education Foundation, Irvine, CA, USA

\section{Key Points}

Psoriasis and comorbid conditions require specialized treatment protocols with respect to the safety and efficacy of biologics to achieve treatment goals.

Clinical trials have led to newly approved biologics for the treatment of moderate-to-severe psoriasis, providing unique treatment options for patients with psoriasis and comorbid conditions; initial biologic treatment choice varies with disease severity, clinical presentation, and patient preferences.

We provide evidence-based recommendations for consideration in patients with concurrent psoriasis and active coronavirus disease 2019 (COVID-19) infection. 
psoriasis include tumor necrosis factor inhibitors (TNFi: infliximab, etanercept, adalimumab, certolizumab pegol), interleukin (IL)-17 inhibitors (secukinumab, ixekizumab, brodalumab), an IL-12/23 inhibitor (ustekinumab), and IL-23p19 inhibitors (guselkumab, tildrakizumab, risankizumab) [4, 5]. Moreover, several biologics (e.g., bimekizumab and mirikizumab) and small-molecule therapies (deucravacitinib) are in development, complicating treatment decisions. We aim to provide an update of the evidence-based treatment recommendations for individuals with psoriasis.

\section{Approach to the Evidence}

Our review objective was to create evidence-based treatment algorithms derived from existing literature. We provide biologic treatment algorithms for moderate-to-severe psoriasis in patients with comorbidities and in special populations. Treatment algorithms are organized as follows:

- Medications within a biologic class and with similar efficacy and safety profiles are separated by commas.

- If all of the drugs of a class are assigned equal weight, the class is listed (e.g., IL-17 inhibitors) in place of individual biologic agents.

\section{Comorbid Conditions and Special Populations}

Important considerations:

- Our recommendations are not definite. Physicians should create an optimal treatment plan with respect to patientrelated factors and comorbid conditions.

- For clinical scenarios lacking high-quality evidence from large-scale randomized controlled trials (RCTs), lowerquality studies, including case reports, proof-of-concept studies, and studies with small sample sizes are utilized.

- Barriers to patient care, such as transport and insurance, are not taken into consideration.

\subsection{Patients with Psoriasis and Psoriatic Arthritis}

PsA affects 20-30\% of patients with psoriasis [1, 7-9]. Since psoriasis can occur concurrently with or as a predecessor to PsA, early detection and referral to rheumatologists is essential to preserve joint function and prevent debilitating joint damage $[1,10]$.

A phase IIIB/IV RCT compared ixekizumab $(n=283)$ and adalimumab $(n=283)$ in patients with PsA and active psoriasis ( $\geq 3 \%$ of body surface area) for 24 weeks [11]. Ixekizumab maintained superior efficacy compared with adalimumab for $100 \%$ improvement from baseline in the Psoriasis Area and Severity Index (PASI100) (ixekizumab $60.1 \%$, adalimumab $46.6 \% ; p=0.001$ ) and $50 \%$ improvement from baseline in American College of Rheumatology criteria (ACR50) (ixekizumab 50.5\%, adalimumab 47\%; $p=0.338$ ) with fewer severe adverse events (AEs) (ixekizumab $3.5 \%$, adalimumab $8.5 \%$ ) [11]. Through 52 weeks, $64.3 \%$ of patients receiving ixekizumab and $41.3 \%$ of those receiving adalimumab achieved PASI100 ( $p<0.001)$; responses in terms of ACR50 were similar for both drugs (49.8 vs. 49.8\%; $p=0.924)$ [12]. Ixekizumab showed improvement in quality-of-life measures and a moderate safety profile in PsA with comorbid psoriasis in two phase III RCTs $[13,14]$. Another phase III RCT $(n=996)$ evaluated secukinumab $150 \mathrm{mg} / 300 \mathrm{mg}$, with or without a loading dose (LD), compared with placebo in patients with PsA and concomitant psoriasis [15]. Patients receiving secukinumab $300 \mathrm{mg}$ with LD $(p<0.01), 150 \mathrm{mg}$ without LD $(p<0.01)$, and $150 \mathrm{mg}$ with LD $(p<0.05)$ experienced significant clinical improvement in PsA, and radiologic progression was inhibited by week 24, with AE rates (approximately 62\%) comparable across all four treatment arms [15]. The low rate of radiologic progression was maintained through week 156 in patients with and without psoriasis [16-18]. In a phase IIIb RCT $(n=853)$ in patients with PsA and comorbid psoriasis evaluating secukinumab compared with adalimumab, secukinumab did not show significant superiority over adalimumab (PASI90, $p<0.001$; ARC50 $p<0.2251$ ) [19].

In two phase III RCTs (PSUMMIT 1 AND 2; $n=546$ psoriasis and PsA/747 total PsA), ustekinumab resulted in decreased radiologic progression compared with placebo [20]. Additionally, more patients receiving ustekinumab 45 or $90 \mathrm{mg}$ experienced complete resolution of enthesitis and dactylitis by week 24 compared with placebo [20]. Analysis of the BIOPURE (Biologic Apulian) registry $(n=160)$ showed longer 12-month drug survival of ustekinumab and better clinical outcomes in TNFi-naïve patients with PsA [21].

In the phase III DISCOVER-1 RCT $(n=362)$ and phase II RCT ( $n=149$ ), guselkumab led to significant improvements in physical function and psoriasis [22, 23]. Additionally, guselkumab maintained a stable safety profile in phase III RCTs [24, 25].

The follow-up time is longer for TNFi than for IL-17 inhibitors and IL-12/23 inhibitors [10]. TNFi are among the first choices for PsA because the clinical evidence supporting efficacy and inhibition of radiologic progression is consistent [26, 27]. Guselkumab is the second-line treatment as it has proven efficacy and mild side effects [28]. Ustekinumab is the third-line treatment option as several studies have shown efficacy for PsA. Phase III trials are ongoing for IL-23 inhibitors (tildrakizumab) and IL-17 inhibitors (brodalumab) for approval in PsA [29, 30]. 
Expert opinion algorithm:

1. TNFi or IL-17 inhibitors

2. Guselkumab

3. Ustekinumab

\subsection{Patients with Psoriasis and Multiple Sclerosis}

Individuals with psoriasis may have increased risk for MS because of an overactive immune system [31, 32]. TNFi are not recommended for individuals with MS or with a firstdegree relative with MS [31, 33-41].

IL-17 inhibitors have been shown to reduce MS lesion activity on radiographic studies $[5,31,42]$. In a phase II RCT $(n=73)$ to assess the effects of secukinumab on number of new active lesions in patients with MS, secukinumab significantly reduced the number of unique active MS lesions compared with placebo [42]. In a case study of concomitant psoriasis and MS, secukinumab reduced psoriasis activity, but the patient experienced severe MS relapse [43]. In three additional reports, secukinumab achieved clinical improvement in psoriasis without MS progression [44-46]. Therefore, we recommend IL-17 inhibitors as the first-line treatment [32].

In a phase II RCT $(n=249)$ evaluating ustekinumab for the treatment of patients with MS, ustekinumab was welltolerated but failed to show efficacy in slowing MS progression [47]. A phase III RCT (PHOENIX-1; $n=766$ ), pooled phase II RCTs, and recent case reports $(n=2)$ have all demonstrated ustekinumab to be efficacious for psoriasis without reports of MS or progression of lesions [48-51]. Thus, ustekinumab should be a second-line treatment for patients with psoriasis and MS.

Pooled analysis of three RCTs $(n=2081)$ evaluating the safety of tildrakizumab in psoriasis reported no MS AEs [52]. Two phase III RCTs $(n=997)$ evaluating the safety of risankizumab compared with ustekinumab or placebo did not report any MS cases/exacerbations in patients with psoriasis [53]. Similarly, no cases of MS exacerbation were reported in multiple RCTs with guselkumab [54-56]. The available data for psoriasis with comorbid MS are limited, possibly because patients with MS were excluded from phase III RCTs.

Expert opinion algorithm:

1. IL-17 inhibitors

2. Ustekinumab

3. IL-23 inhibitors

4. Avoid TNFi in patients with MS

\subsection{Patients with Psoriasis and Congestive Heart Failure}

Patients with psoriasis have an increased risk of cardiovascular diseases and new-onset CHF [57, 58]. Currently, TNFi are not recommended in patients with New York Heart Association (NYHA) class III and IV CHF [59-62]. Several case reports have shown new-onset or exacerbation of CHF in patients treated with TNFi $[61,63]$. An RCT $(n=150)$ studying infliximab in NYHA class III or IV CHF indicated that infliximab $10 \mathrm{mg}$ resulted in an increased risk of mortality and hospitalizations compared with placebo (hazard ratio [HR] 2.84; 95\% confidence interval [CI] 1.01-7.97; $p=0.043)[62,64]$. Data from case reports supported similar findings, with patients receiving TNFi experiencing new-onset CHF or exacerbation of symptoms [63]. Before initiation of TNFi in NYHA class I and II CHF, the patient should undergo a cardiology consultation, and clinicians should obtain a baseline echocardiogram to assess ejection fraction $[59,65,66]$. TNFi should be avoided in patients with reduced ejection fraction $<50 \%$ [66]. If CHF worsens or new symptoms develop, TNFi should be discontinued $[5,65,66]$.

A 5-year phase II RCT of brodalumab $(n=181)$ reported no cases of CHF [67]. Moreover, no CHF exacerbations or new-onset $\mathrm{CHF}$ were reported in a 6-month follow-up of patients in the secukinumab registry [68], and no cases of CHF were reported with ixekizumab in three phase III RCTs $(n=3736)[69,70]$.

Two RCTs of ustekinumab, PHOENIX $1(n=601)$ and 2 $(n=849)$, reported no cases of CHF [71, 72].

In a meta-analysis of RCTs, patients initiated on IL-23 or IL-17 inhibitors did not exhibit an increased risk of CHF (risk difference 0.00; 95\% CI -0.01-0.01) [73]; however, the data presented in this study should be evaluated carefully as only the short-term risk of CHF was considered [73].

Expert opinion algorithm:

1. IL-17 inhibitors, IL-23 inhibitors, ustekinumab

2. Avoid TNFi

- Avoid in NYHA class III and IV

- Echocardiogram is recommended in NYHA class I and II

- Avoid in patients with ejection fraction $<50 \%$

\subsection{Patients with Psoriasis and Inflammatory Bowel Disease}

Psoriasis is associated with both Crohn's disease (CD) and ulcerative colitis (UC) [74]. Therapies used for the treatment of psoriasis can potentially exacerbate or induce IBD [74]. 
Likewise, medications used for the treatment of IBD have been noted to worsen psoriasiform lesions [75].

Adalimumab, infliximab, and certolizumab were significantly associated with the induction and maintenance of remission for $\mathrm{CD}$ compared with placebo in a meta-analysis of 19 controlled trials [76]. Adalimumab and infliximab are approved for the treatment of $\mathrm{UC}$ and $\mathrm{CD}$, and certolizumab is approved for the treatment of CD [77]. Adalimumab and infliximab maintained similar treatment persistence levels in UC $(n=160)$ and $\mathrm{CD}(n=487)$ in retrospective observational studies $[78,79]$. In a phase III RCT in patients with $\mathrm{CD}$, infliximab induced clinical remission $(n=75 ; p=0.02)$ and mucosal healing $(n=28 ; p=0.06)$ by week 26 [80]. In a pooled analysis of two RCTs $(n=938)$, adalimumab improved laboratory and quality-of-life markers in UC ( $p$ $<0.05$ and $p<0.001)$ compared with placebo [81]. In a phase III RCT $(n=521)$, adalimumab successfully induced remission for UC compared with placebo [82]. The US FDA Adverse Event Reporting System (FAERS) includes 443 cases of new-onset IBD and 43 cases of IBD exacerbation associated with etanercept [83]. In eight patients, IBD symptoms resolved upon discontinuation of etanercept. Physicians should maintain vigilance for gastrointestinal symptoms [83]. In a nationwide study of autoimmune diseases, etanercept was associated with a significant risk of de novo CD (adjusted HR [aHR] 2.0; 95\% CI 1.4-2.8) and de novo UC (aHR 2.0; 95\% CI 1.5-2.8) [77].

A pooled analysis of 21 controlled trials of secukinumab showed a low incidence of IBD in psoriasis $(n=5181)$, with a total of 20 (14 new-onset) IBD cases [84]. In total, $15 \%$ of patients with psoriasis had prior exposure to biologic therapy with an inadequate response [84]. Pooled data from seven controlled trials of ixekizumab showed a low incidence of IBD in patients with psoriasis (19/4209) [85].

A phase II RCT of brodalumab in 130 patients with active $\mathrm{CD}$ was terminated early because of a disproportionate number of worsening CD cases and lack of efficacy [86]. Thus, brodalumab should be avoided in cases of active CD [86, 87].

Clinicians should prescribe IL-17 inhibitors with caution, as FDA information warns against using the class in IBD [88-90].

In the UNITI- $1 / 2$ RCTs $(n=718)$ in patients with $\mathrm{CD}$, ustekinumab maintained clinical response and remission through week 92 without new safety signals [91]. An endoscopic substudy of RCTs $(n=334)$ showed endoscopic improvement after 8 weeks of ustekinumab treatment ( $p=0.012)$ compared with placebo [92]. However, a cohort study $(n=163)$ comparing adalimumab and ustekinumab reported that adalimumab produced better clinical response (aOR 2.40; 95\% CI 1.14-5.07) and remission rates (aOR 2.35; 95\% CI 1.07-5.16) [93]. Ustekinumab was approved for UC by the FDA in 2019 after a phase III RCT demonstrated effective remission induction and mucosal healing [94].

Currently, trials are investigating IL-23 inhibitors for the treatment of psoriasis with IBD. One RCT comparing risankizumab and secukinumab reported no IBD cases for risankizumab $(n=164)$ and one UC case in patients receiving secukinumab $(n=163)$ [95]. Other studies comparing risankizumab versus ustekinumab, risankizumab versus adalimumab, and guselkumab versus secukinumab also reported no IBD cases [53, 96, 97].

Overall, adalimumab and infliximab should be considered first-line agents for patients with IBD and psoriasis. Ustekinumab and certolizumab have demonstrated efficacy in $\mathrm{CD}$, and ustekinumab was recently approved for UC. IL-23 inhibitors are newly developed biologic agents with good efficacy and safety profiles. Patients should be monitored for symptoms of IBD for up to 4 years after initiation of IL-17 inhibitors [98]. Similarly, etanercept has been reported to induce exacerbation of IBD.

Expert opinion algorithm:

1. Adalimumab, infliximab (approved for CD and UC)

2. Certolizumab (approved for $\mathrm{CD}$ ), ustekinumab (approved for CD and UC)

3. IL-23 inhibitors

4. Etanercept

5. Avoid IL-17 inhibitors in patients with IBD

\subsection{Patients with Psoriasis and Hepatitis B}

Over 250 million people worldwide are infected with hepatitis $B$ virus (HBV), with chronic infection resulting in severe complications $[99,100]$. As biologics are immunosuppressive agents, concern remains for reactivation of HBV. To ensure appropriate treatment recommendations, HBV screening with triple serology (including hepatitis surface antigen [HBsAg], antibodies to hepatitis core antigen [anti$\mathrm{HBc}]$, and antibodies to hepatitis surface antigen [anti-HBs]) and liver function tests (LFTs) are recommended before initiation of biologics [101].

TNFi are associated with a risk of HBV reactivation and drug-induced liver injury, especially in HBsAg-positive patients with psoriasis [102, 103]. Seropositivity for HBsAg has a higher risk without antiviral prophylaxis (12-39\%) than with antiviral prophylaxis $(1-10 \%)$. The risk is lower with seropositivity anti-HBc [102, 103]. A multicenter study of patients with psoriasis with hepatitis B $(n=359)$ or hepatitis $\mathrm{C}(n=61)$ treated with two or more immunosuppressants (including biologics) $(p=0.0223)$ reported the following predictive factors for viral reactivation: HBsAg-seropositivity $(p<0.0001)$, hepatitis B e-antigen positivity $(p=0.0134)$, and absence of antiviral prophylaxis ( $p=0.046)$ [104]. The study also supported a lower risk of 
reactivation with antiviral prophylaxis and recommended viral load monitoring. The risk of reactivation was higher with TNFi than with IL-17 inhibitors (aHR 2.67; 95\% CI 1.08-6.58) [104]. A retrospective cohort study $(n=30)$ and systematic review (49 studies, $n=312$ ) evaluated patients with hepatitis $\mathrm{B}$ or $\mathrm{C}$ with psoriasis receiving biologic therapy [105]. Yearly reactivation rates were higher in patients with chronic hepatitis B (13.92\%) than with patients with resolved hepatitis B $(0.32 \%)$ on TNFi therapy, and the risk was higher in patients who did not receive antiviral prophylaxis $(26.31 \%)$ [105].

A 1-year brodalumab pharmacovigilance update $(n=826)$ reported no cases of hepatitis B; further data are needed to evaluate the safety profile [106]. Three phase III RCTs $(n=3736)$ demonstrated the clinical efficacy of ixekizumab for patients with psoriasis, with no reported cases of hepatitis B reactivation through week 60 [70]. In a prospective secukinumab cohort study with 49 patients with hepatitis B, HBsAg-positive patients had a higher risk of reactivation than $\mathrm{HBs}-\mathrm{Ag}$-negative and $\mathrm{HBcAg}$-positive patients (24.0 vs. $4.17 \% ; p=0.047$ ) [107]. However, reactivation rates were lower with antiviral prophylaxis $(0 \%)$ than without $(15.2 \%)$ for the same groups. Patients on secukinumab should receive antiviral prophylaxis to prevent viral reactivation and routine monitoring for HBV viral load [107].

In a prospective cohort study ( $n=93)$ of ustekinumab in patients with psoriasis, inactive HBV carriers experienced a reactivation rate of $17.4 \%$ without antiviral prophylaxis compared with no cases with prophylaxis [108]. One patient with reactivation was concurrently treated with methotrexate [108]. Two additional retrospective cohort studies concluded ustekinumab was safe and efficacious to use in patients with psoriasis and hepatitis B with proper monitoring and antiviral prophylaxis $[109,110]$. As studies of viral hepatitis and psoriasis are limited to small sample sizes, further data from RCTs are needed to evaluate the safety and efficacy of ustekinumab in psoriasis with concomitant hepatitis B.

No trials have specifically studied IL-23 inhibitors in patients with psoriasis and hepatitis [111-113]. However, a phase III RCT $(n=739)$ evaluating guselkumab in PsA reported one case of hepatitis B [25]. Another phase III RCT of guselkumab $(n=381)$ in patients with PsA reported no cases of hepatitis B [22]. Analyses of phase III RCTs with tildrakizumab and risankizumab also reported no cases of hepatitis [53, 114]. As IL-23 inhibitors are a novel class of drugs with no to minimal reported cases of hepatitis B in RCTs, we recommend this class as a second-line treatment.

Overall, before immunosuppressive therapy is initiated, especially TNFi, we recommend consultation with a hepatologist and triple serology screening with LFTs in all patients with psoriasis with a history of hepatitis B [5, $102,105,115,116]$. Serologic risk stratification between nonimmune, immune due to vaccination, resolved previous hepatitis infection, acute infection, chronic infection, and occult infection will allow appropriate initiation of antiviral prophylaxis and/or vaccination. Further, antiviral prophylaxis and testing for HBV reactivation should be continued for 6-12 months after biologic therapy cessation [117].

Expert opinion algorithm:

1. IL-17 inhibitors

2. IL-23 inhibitors

3. Ustekinumab or TNFi

\subsection{Patients with Psoriasis and Latent Tuberculosis}

Screening for latent tuberculosis infection (LTBI) and a full clinical history/physical examination are recommended for patients with psoriasis prior to initiation of biologics [118, 119]. Patients should be asked about recent exposure to tuberculosis, treatment history, and treatment course/compliance [118]. A tuberculin skin test or an interferon gamma assay are strongly recommended before initiation of biologic therapy [119]. If clinical suspicion is high, patients should receive a chest X-ray [119]. In LTBI diagnosis, prophylactic treatment with isoniazid $300 \mathrm{mg}$ and vitamin $\mathrm{B}_{6} 50 \mathrm{mg}$ for 9 months is advised [5, 119]. However, patients with LTBI can be started on biologics after 1-2 months of LTBI prophylaxis and demonstrated treatment compliance/tolerance if needed [119].

The use of TNFi in rheumatologic and dermatology conditions, including PsA, has been associated with serious tuberculosis infection [65, 120-122]. The World Health Organization issued a black box warning for the risk of tuberculosis and other serious infections with TNFi [123]. Further, a review indicated patients with LTBI treated with TNFi have an approximately two to four times increased risk of developing active tuberculosis [124]. A pooled analysis of controlled trials for numerous conditions yielded one case of tuberculosis in patients on certolizumab [125]. A metaanalysis of 29 RCTs reported that $45 / 7912(0.57 \%)$ patients developed tuberculosis after treatment with TNFi [126]. Over a 7-year period, six cases of active tuberculosis were reported in adult patients with psoriasis on adalimumab in the ESPIRIT registry $(n=6051)$ [127]. A study analyzing adalimumab safety data from 18 controlled trials reported 16 cases of tuberculosis (seven LTBI, nine active tuberculosis) in 3723 patients with psoriasis [128]. A similar study that analyzed 77 controlled trials of adalimumab for various conditions reported a tuberculosis incidence rate (IR) of 0.2 in patients with psoriasis $(n=3732)$ [129]. Analysis of infliximab treatment for dermatologic and rheumatologic conditions revealed 70 cases of active tuberculosis after treatment initiation in FAERS [130].

The following cases of tuberculosis reactivation have been reported: 0/826 in a 1-year pharmacovigilance study 
of brodalumab, 0/5898 in cumulative data from 13 clinical trials of ixekizumab, 0/2044 in an analysis of pooled safety data from five RCTs of secukinumab, 0/3430 in an analysis of pooled safety data in ten RCTs of secukinumab, and one patient without prophylaxis/3117 in an analysis of pooled safety data from four RCTs of ustekinumab [49, 106, 131-133]. Furthermore, five pooled phase III RCTs of ustekinumab $(n=3177)$ reported no cases of LTBI reactivation with antituberculosis prophylaxis [134].

Two phase III RCTs of guselkumab reported no cases of LTBI reactivation or active tuberculosis compared with two cases of LTBI reactivation with adalimumab in patients with psoriasis [135]. Four phase III RCTs of risankizumab reported no cases of active tuberculosis [53, 95, 96]. Two phase III tildrakizumab RCTs reported no cases of tuberculosis [114].

Evaluation of LTBI before initiating biologic therapy, as well as follow-up and routine monitoring with antiviral prophylaxis, are indicated [5, 88-90, 111-113, 136-140]. As low rates of tuberculosis reactivation have been reported with IL-23 and IL-17 inhibitors, and their long-term safety profiles are favorable, they are first in our algorithm. Since TNFi increase the risk of serious tuberculosis infection, this class is a last-line option. At least 1 month of antiviral prophylaxis is recommended before initiating ustekinumab and TNFi therapy.

Expert opinion algorithm:

1. IL-17 inhibitors or IL-23 inhibitors

2. Ustekinumab or TNFi after tuberculosis prophylaxis

\subsection{Pediatric Patients with Psoriasis}

Psoriasis accounts for approximately $4 \%$ of pediatric dermatoses, with up to $33 \%$ of cases starting in childhood [141]. Pediatric patients with psoriasis are reported to have double the occurrence of comorbidities than their peers [141]. Pediatric patients have previously been managed according to data from adult controlled trials, but pediatric controlled trials are emerging to help guide management [142]. However, caution is still advised when prescribing biologics for psoriasis treatment [5].

Weekly etanercept is approved for the treatment of patients aged $\geq 4$ years with moderate-to-severe psoriasis [141]. A retrospective cohort study examining patients aged $\leq 17$ years $(n=23)$ receiving etanercept reported that $56.5 \%$ achieved PASI 75 and $86.9 \%$ achieved PASI50 by week 12 , with treatment efficacy maintained at week 52 [143]. PASI75 and PASI 90 were maintained by approximately $65 \%$ and $35 \%$ of patients, respectively, through 5 years in an openlabel extension study (69/181) [144]. AEs were reported by $161(89.0 \%)$ of the patients and included upper respiratory tract infection $(37.6 \%)$, nasopharyngitis $(26.0 \%)$, and headache (21.55\%), with seven patients experiencing eight severe AEs [144]. Limitations include the small number of patients completing the study through week 264 [144, 145]. With a high percentage of patients affected by AEs, etanercept is third in our algorithm.

The European Medicines Agency (EMA) approved adalimumab for the treatment of psoriasis in patients aged $\geq 4$ years. A retrospective observational study involving 134 patients compared etanercept $(n=63)$, adalimumab $(n=44)$, and ustekinumab $(n=27)$ [146]. The drug survival rate was highest for ustekinumab compared with etanercept and adalimumab $(p<0.0001)$. Severe AEs of infections and weight gain were reported with adalimumab (six) and etanercept (one) [146]. A phase III RCT treated 114 pediatric patients with psoriasis (aged $>4$ and $<18$ years) with either adalimumab $0.8 \mathrm{mg} / \mathrm{kg}(n=38), 0.4 \mathrm{mg} / \mathrm{kg}(n=39)$, or methotrexate $(n=37)$ [147]. After 16 weeks, adalimumab $0.8 \mathrm{mg} / \mathrm{kg}$ resulted in significant improvement to PSAI75 (58\%) compared with methotrexate $(32 \%)(p=0.027)$ [147]. All three treatment groups experienced similar AE profiles, with the majority being infections [147].

Ixekizumab is an alternative agent for pediatric psoriasis, with a favorable dosing schedule of every 4 weeks [148]. In a phase III RCT, 171 patients (aged 6 to $<18$ years) with moderate-to-severe psoriasis were treated with ixekizumab $(n=115)$ or placebo $(n=56)$. At week $12,89 \%$ of patients on ixekizumab achieved PASI75 compared with $25 \%$ of patients on placebo $(p<0.001)$, and $81 \%$ of those on ixekizumab achieved static Physicians Global Assessment (PGA) $0 / 1$ compared with $11 \%$ on placebo $(p<0.001)$ [148]. At week 48, a treatment response of PASI75 was reported in $103(90 \%)$ and a PGA of $0 / 1$ in $93(81 \%)$ patients $(p<0.001)$. Less than $7 \%$ of patients experienced serious AEs, with infections being the most common [148]. Thus, ixekizumab should be considered a second-line treatment.

Ustekinumab was approved for the treatment of moderate-to-severe psoriasis in the pediatric population aged $\geq 6$ years [138]. The drug has a favorable dosing schedule of a subcutaneous injection every 12 weeks once the second dose has been given 4 weeks after the first [138]. A phase III RCT evaluated ustekinumab in 110 patients aged 12-17 years [149]. The study evaluated placebo compared with half standard dose (HSD) or standard dose (SD) ustekinumab. The results showed patients achieving PGA 0/1 (HSD 67.6\%, SD $69.4 \%$, placebo $5.4 \%$ ), PASI75 (HSD $78.4 \%$, SD 80.6\%, placebo $10.8 \%$ ), or PASI90 (HSD 54.1\%, SD 61.1\%, placebo $5.4 \%)$ by week $12(p<0.001)[5,149]$. Furthermore, clinical results were similar to those in adults, with no unexpected AEs [149]. A recent open-label phase III controlled trial evaluated ustekinumab in 44 patients aged 6-12 years. At week 12, a total of 34 (77\%; 95\% CI 62.2-88.5) patients had achieved PGA 0/1, 37 (84\%; 95\% CI 69.9-93.4) patients had achieved PASI75, and 28 (64\%; 95\% CI 47.8-77.6) patients 
had achieved PASI90. Ustekinumab was well-tolerated, with clinical responses similar to those in the CADMUS adult study $[149,150]$. Limitations included the small population size, which affects the generalizability of the results. Therefore, in pediatric patients with moderate-to-severe psoriasis, ustekinumab should be considered a first-line treatment.

Further controlled trials are underway to evaluate the efficacy and safety of biologics in pediatric patients with psoriasis. In 2020, secukinumab was approved in the EU for pediatric psoriasis (patients aged 6 to $<18$ years) [151]. The long-term effects and complications of biologic agents may vary in the pediatric population.

Expert opinion algorithm:

1. Ustekinumab (age $\geq 6$ years)

2. Ixekizumab (age $\geq 6$ years)

3. Etanercept (age $\geq 4$ years)

4. Adalimumab (Europe: age $\geq 4$ years)

\subsection{Psoriasis in Patients with Childbearing and Breastfeeding Potential}

The majority of patients present with psoriasis before the age of 40 years, correlating with the reproductive years [152]. Although half of pregnant patients report clinical improvement in psoriasis, an equal number report a lack of clinical change or worsening [153]. In general, systemic agents such as biologics are not indicated during conception, pregnancy, and breastfeeding as the full safety profile remains unknown because of the lack of evidence and inconsistent data [153, 154]. Discontinuing biologics remains challenging, as cessation can lead to exacerbation of underlying psoriasis [155]. Pre-conception counseling is essential because of the risk of drug-induced teratogenicity [154].

A population-based study by the FDA and the EMA evaluated the prevalence of preterm birth, intrauterine growth restriction (small for gestational age [SGA]), and cesarean section with TNFi $(n=1027)$ or nonbiologic systemic (NBS) treatment $(n=9399)$ during pregnancy [156]. The study was stratified by IBD (CD and UC) and ARTPSO (rheumatoid arthritis, ankylosing spondylitis, PsA, and psoriasis) to compare infliximab, adalimumab, and etanercept. Comparing TNFi and NBS groups, the TNFi group exhibited a higher risk of preterm birth (adjusted odds ratio [aOR] 1.61; 95\% CI 1.29-2.02), severely SGA (aOR 1.36; 95\% CI 0.96-1.92), and cesarean section (aOR 1.57; 95\% CI 1.35-1.82) [156]. The ARTPSO group had a significantly higher risk of preterm birth (aOR 1.42; 95\% CI 1.03-1.97), severely SGA (aOR 1.62; 95\% CI 1.09-2.41), and cesarean section (aOR 1.57; 95\% CI 1.35-1.82) [156]. Furthermore, in ARTPSO, infliximab was associated with a greater risk of preterm birth than were etanercept and adalimumab. Infliximab had a higher prevalence of severe SGA than etanercept and adalimumab in the ARTPSO group. A greater risk of preterm birth was observed in pregnant women who used TNFi therapy in the first trimester [156]. Data from Janssen's global surveillance database indicated that the prevalence of adverse pregnancy and infant ( $<2$ years) outcomes in the general population was comparable to that with infliximab exposure for numerous conditions [157]. Furthermore, if TNFi are administered during pregnancy, live vaccinations should be withheld in infants within the first 6-12 months of life $[158,159]$.

The Organization of Teratology Information Specialists (OTIS) analyzed adalimumab in the first trimester of pregnancy in patients with autoimmune conditions and reported a rate of major birth defects of $10 \%$ in adalimumab-exposed patients compared with $7.5 \%$ in the diseased but unexposed cohort [160]. OTIS did not report significant increases in structural defects, pregnancy complications, or fetal and infant adverse health outcomes, although the risk of preterm delivery increased [160]. FDA information showed active placental transfer of adalimumab during the third trimester and a presence in infants for up to 3 months after birth. However, adalimumab is hypothesized to be safe during breastfeeding because of its large molecule size [136].

Certolizumab pegol has demonstrated no to minimal placental transfer during the last two terms of pregnancy [5, 161, 162]. The lack of an Fc domain, unlike other TNFi, prevents binding to neonatal $\mathrm{Fc}$ receptors, minimizing placental transfer $[157,161]$. In a prospective pharmacokinetic study of chronic inflammatory diseases, 1 in 14 infants had minimal levels and 13 had no quantifiable levels of certolizumab [161]. Further, at 4 and 8 weeks after delivery, none of the infants had quantifiable levels of the drug, indicating the safety of certolizumab in the third trimester [161]. A chronic inflammatory disease safety database study of 528 pregnancies with maternal exposure to certolizumab did not report an increased risk of teratogenic effect or fetal death compared with the general population [162]. In a pharmacokinetic study of various diseases $(n=17)$, certolizumab was safe during breastfeeding, with minimal transfer to breast milk [163]. Thus, in pregnant and breastfeeding women, certolizumab is a first-line treatment.

Data on the use of ustekinumab and secukinumab in pregnancy are limited [89, 138]. Case reports of five patients with psoriasis treated with ustekinumab demonstrated one first trimester pregnancy loss and four uncomplicated pregnancies [164]. Further, birth defect and pregnancy loss rates were similar to those in non-ustekinumab users in pregnancy. The low transfer rate of ustekinumab in breastfeeding is hypothesized as being due to its large molecular size [165]. Similarly, a secukinumab 7-week follow-up study $(n=6)$ reported an acceptable safety profile but recommended secukinumab only if benefits outweigh risks [89, 166]. Analysis of a secukinumab registry and pooled data 
did not find an increased rate of congenital abnormalities or adverse pregnancy outcomes $[167,168]$. Thus, secukinumab and ustekinumab are second-line treatments.

Data on brodalumab and ixekizumab in pregnancy are limited. Both IL-17 inhibitors are monoclonal immunoglobulin (IgG) antibodies, which have been known to cross the placenta and be excreted into breast milk [169, 170]. No data on the efficacy and safety of brodalumab in pregnant humans are available [90]. Exposure to ixekizumab was found to have no significant effect on pregnancy outcomes $(n=58)$ in the US PSOLAR (epidemiologic and Psoriasis Longitudinal Assessment and Registries) [171]. Given the limited evidence, brodalumab and ixekizumab are considered lastline treatments.

Research on the use of IL-23 inhibitors in pregnancy is limited. Tildrakizumab, risankizumab, and guselkumab are monoclonal IgG antibodies that can cross the placenta and be transported into human milk during lactation [111-113]. Preliminary data indicate that safety and adverse event profiles are similar to those of older biologic agents [172]. Given the risk of adverse developmental outcomes, IL-23 inhibitors are last-line treatments [172].

Expert opinion algorithm (note that the authors do not fully agree with \#2-4 in this treatment algorithm):

1. Certolizumab

2. Ustekinumab or secukinumab

3. Adalimumab, etanercept, or infliximab

4. Ixekizumab, brodalumab, or IL-23 inhibitors

\subsection{Patients with Psoriasis and History of Malignancy}

Patients with psoriasis are reported to have an increased risk of malignancy, particularly lymphoma and nonmelanoma skin cancer (NMSC) [173-177]. Consequently, age-appropriate routine cancer screening is especially important in patients with psoriasis on immunosuppressive therapies [2].

As TNFi regulate tumor growth factor, concerns remain for malignancy with the use of these drugs [178]. Three meta-analyses and an observational study of multiple conditions, including psoriasis, reported an increased risk of NMSC and/or lymphoma with the use of TNFi [179-182]. The risk of lymphoma (OR 2.14; 95\% CI 0.55-8.38) was higher than that of NMSC (OR 1.37; 95\% CI 0.59-3.19) in a meta-analysis of rheumatoid arthritis [183]. However, in a large cohort study of various conditions, TNFi did not have a recurrent cancer risk [184].

A pooled analysis of ten controlled trials of secukinumab in psoriasis $(n=3430)$ showed no significant risk of malignancy, with three NMSC cases and no lymphoma cases [133]. Similarly, analysis of safety data from seven controlled trials of ixekizumab in patients with psoriasis $(n=4209)$ reported 27 cases of NMSC and two cases of lymphoma [185]. In a pooled analysis of three RCTs $(n=4019)$ in patients treated with brodalumab, three reported NMSC and two reported lymphomas [186].

Four pooled controlled trials $(n=3225)$ evaluating ustekinumab 45 or $90 \mathrm{mg}$ compared with controls reported 39 cases of NMSC and one case of lymphoma [187]. Given the low risk of NMSC and lymphoma associated with ustekinumab, we recommend this biologic as a first-line treatment [49, 187].

Three cases of NMSC and no lymphoma cases were reported with guselkumab compared with adalimumab and placebo in two psoriasis RCTs [54, 56]. A pooled analysis of two psoriasis RCTs reported 20 cases of NMSC and no cases of lymphoma after 148 weeks of cumulative exposure to tildrakizumab 100 and $200 \mathrm{mg}$ [114]. Furthermore, with risankizumab, the IR of NMSC was 0.3 , and no cases of lymphoma were reported [53, 188]. We recommend IL-17 inhibitors and IL-23 inhibitors as second-line treatments in our algorithm.

Expert opinion algorithm:

1. Ustekinumab

2. IL-17 inhibitors or IL-23 inhibitors

3. TNFi in NMSC; avoid TNFi in lymphoma

\subsection{Patients with Psoriasis and Coronavirus Disease 2019 (COVID-19)}

Severe acute respiratory syndrome coronavirus 2 (SARSCoV-2; coronavirus disease 2019 [COVID-19]) is an evolving health emergency [189]. Although vaccines for COVID19 are now available, over 2.8 million deaths have occurred globally at the time of writing (https://covid19.who.int/) [189-191]. Despite concerns over increased susceptibility for opportunistic infections, there is limited evidence on the implications of biologic treatments with COVID19 [192-194]. Withholding biologics and transitioning to safer alternatives may be considered to avoid complications, and initiation of biologic therapy is not recommended in active SARS-CoV-2 infection [195-198]. Moreover, patients should be carefully assessed before a biologic is discontinued because of the risk of diminished treatment response with re-initiation and the development of antibodies, erythroderma, or disease flare [196, 199]. Our treatment algorithm focuses on patients who are negative for COVID-19 and are not at high-risk for SARS-CoV-2 infection.

Two cases have been reported of patients with psoriasis receiving biologics who achieved full recovery from COVID-19 with outpatient supportive therapy [199]. One patient started ustekinumab 3 years prior to COVID-19 diagnosis. These reports should be interpreted with caution as 
both patients were aged $<60$ years and were without established risk factors for COVID-19 [199].

Presently, clinical data are lacking for the safety of biologic therapy effects with SARS-CoV-2 infections. Analysis of PSOLAR $(n=11,466)$ showed an overall IR of 1.45 per 100 patient-years for serious infections for biologics and nonbiologics [200]. Pneumonia and cellulitis were the most commonly reported infections, with the following IRs per 100 patient-years for infections: ustekinumab (0.83), etanercept (1.47), adalimumab (1.97), and infliximab (2.49) [200]. The rates of serious infection were lowest for ustekinumab and etanercept and higher for adalimumab and infliximab [200]. A prospective cohort study did not report statistically significant higher infection rates for patients with psoriasis on etanercept ( $n=1352)$, adalimumab $(n=3271)$, and ustekinumab $(n=994)$ compared with nonbiologic therapies $(n=3421)$ [201]. Etanercept (HR 1.10; 95\% CI 0.75-1.60) had a higher risk of serious infection than adalimumab (HR 1.26; 95\% CI 0.86-1.84) and ustekinumab (HR1.22; 95\% CI 0.75-1.99) [201]. In three phase III RCTs in psoriasis $(n=1146)$, rates of serious infections with certolizumab were comparable to those with placebo $[202,203]$.

Two phase III RCTs in psoriasis evaluated the role of risankizumab compared with placebo and ustekinumab [53]. Risankizumab had a similar safety profile but superior treatment efficacy to placebo and ustekinumab [53]. Infections were the highest reported adverse event, with less than $3 \%$ of treatment groups being affected with serious infections [53]. Analysis of pooled data from three RCTs in psoriasis $(n=2081)$ showed a lower frequency of infection with tildrakizumab $100 \mathrm{mg}$ (48.9) and $200 \mathrm{mg}$ (52.6) compared with placebo (86) and etanercept (79.5) when adjusted for exposure [52]. Infection rates for guselkumab were similar to those for placebo and adalimumab [54]. As IL-23 inhibitors have low rates of infection compared with $\mathrm{TNFi}$, they are considered first-line treatments in psoriasis and COVID-19. Ustekinumab similarly had low rates of infection so is also a first-line treatment.

Increased levels of IL-17 in acute respiratory distress syndrome have been implicated in lung parenchyma damage and edema through recruiting of neutrophils [204, 205]. Inhibition of IL-17 has potential as a COVID-19 treatment and as a biomarker for lung disease severity [204, 205]. However, prescribing information for secukinumab, brodalumab, and ixekizumab note an increased infection risk [88-90]. RCTs reported an increased risk of upper respiratory tract infection with secukinumab and ixekizumab and a lower risk with brodalumab [204-206]. If severe viral symptoms with high fever develop, clinicians should consider discontinuing biologics [204-208]. Overall, we consider IL-17 inhibitors to be last-line options in our treatment algorithm.
Given the relative novelty of COVID-19, we urge physicians to use our treatment algorithm as a guide. As COVID19 research is rapidly evolving, therapeutic recommendations should be monitored with vigilance.

Expert opinion algorithm:

1. IL-23 inhibitors or ustekinumab

2. TNFi

3. IL-17 inhibitors

\section{Discussion}

New RCTs, postmarketing surveillance data, and approval of additional biologic classes have increased the treatment options available for moderate-to-severe psoriasis. This review provides first-line treatment recommendations for managing psoriasis in several clinical scenarios (Table 1).

Since IL-23 inhibitors were recently approved for the treatment of psoriasis, postmarketing trials are needed to confirm their safety and efficacy. Mirikizumab, another IL23 p19 inhibitor, has yet to be approved for psoriasis treatment, but preliminary results are promising $[209,210]$. The RCTs OASIS- $1(n=530)$ and OASIS- $2(n=1484)$ compared mirikizumab with placebo and secukinumab and demonstrated superior efficacy for mirikizumab, with results sustained at week 52 [209-211]. Rates of severe AEs remained $<6 \%$ [211]. Recent RCTs have also supported the efficacy of biosimilars compared with originator drugs; however, utilization in the USA has yet to gain momentum [212-216].

A limitation of this article is the potential subjective selection bias for pivotal pertinent articles. Moreover, data from phase III RCTs may be biased because of the selective enrollment criteria. A strength is the breadth of literature included, with a large number of RCTs evaluated.

The indications and limitations of each biologic need to be carefully considered while creating a treatment protocol. As stronger evidence emerges, the treatment algorithm should be modified accordingly.

\section{Conclusion}

Selection of treatments for moderate-to-severe psoriasis with comorbid conditions is complex and requires careful consideration of numerous factors (i.e., costs, patient preferences, and disease severity). Our algorithms may serve as a guide when choosing a biologic for patients with comorbid PsA, MS, CHF, IBD, hepatitis B, LTBI, lymphoma, NMSC, or COVID-19 or in pregnant or pediatric patients. 


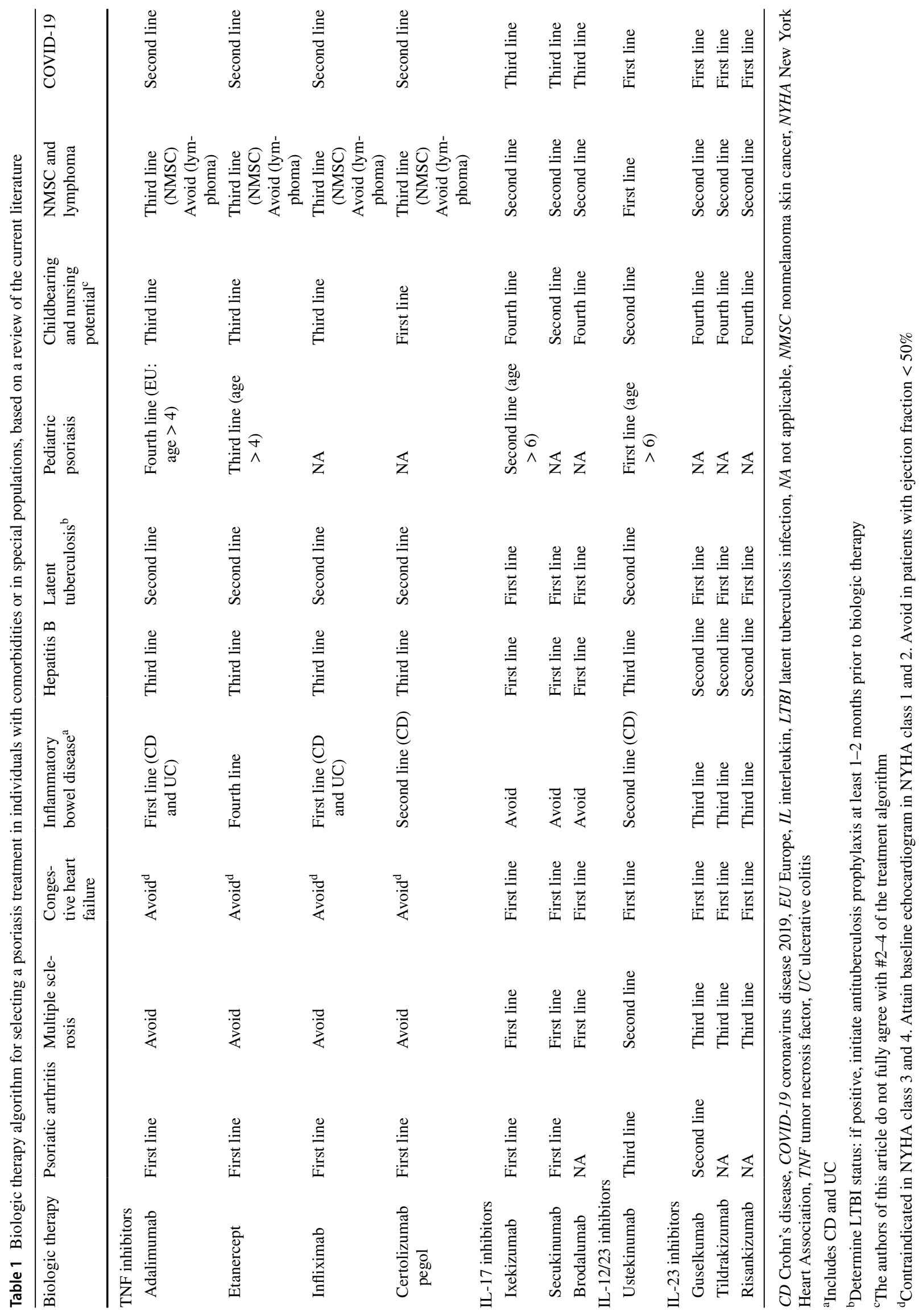


Acknowledgements The authors would like to acknowledge Dr. Mina Amin and Dr. Daniel No, who were authors on a previously published manuscript from which this paper was developed.

\section{Declarations}

Funding No sources of funding were used to conduct this study or prepare this manuscript.

Conflict of interest Ms. Thatiparthi, Mr. Liu, and Ms. Martin have no conflicts of interest that are directly relevant to the content of this article. Dr. Wu is or has been an investigator, consultant, or speaker for AbbVie, Almirall, Amgen, Arcutis, Aristea Therapeutics, Boehringer Ingelheim, Bristol-Myers Squibb, Dermavant, Dr. Reddy's Laboratories, Eli Lilly, Galderma, Janssen, LEO Pharma, Mindera, Novartis, Regeneron, Sanofi Genzyme, Solius, Sun Pharmaceutical, UCB, Valeant Pharmaceuticals North America LLC, and Zerigo Health. Dr. Egeberg has received research funding from Pfizer and Eli Lilly and honoraria for work as a consultant and/or speaker from Pfizer, Eli Lilly, Novartis, Galderma, and Janssen Pharmaceuticals.

Ethics approval Not applicable.

Consent to participate Not applicable.

Consent to publish Not applicable.

Availability of data and material Data obtained from public domain resources.

Code availability Not applicable.

Author contributions Initial concept by JJW and AT. AT, AM, and JL characterized and wrote the manuscript with oversight by AE and JJW. All authors discussed the results, read, and approved the final manuscript.

\section{References}

1. Ocampo DV, Gladman D. Psoriatic arthritis. F1000Res. 2019;2019:8.

2. Takeshita J, Grewal S, Langan SM, Mehta NN, Ogdie A, Van Voorhees AS, et al. Psoriasis and comorbid diseases: epidemiology. J Am Acad Dermatol. 2017;76(3):377-90.

3. Griffiths CEM, van der Walt JM, Ashcroft DM, Flohr C, Naldi L, Nijsten T, et al. The global state of psoriasis disease epidemiology: a workshop report. Br J Dermatol. 2017;177(1):e4-7.

4. Strober B, Karki C, Mason M, Guo N, Holmgren SH, Greenberg JD, et al. Characterization of disease burden, comorbidities, and treatment use in a large, US-based cohort: results from the Corrona Psoriasis Registry. J Am Acad Dermatol. 2018;78(2):323-32.

5. Amin M, No DJ, Egeberg A, Wu JJ. Choosing first-line biologic treatment for moderate-to-severe psoriasis: what does the evidence say? Am J Clin Dermatol. 2018;19(1):1-13.

6. Rønholt K, Iversen L. Old and new biological therapies for psoriasis. Int J Mol Sci. 2017;18(11):2297.

7. Liu J, Thatiparthi A, Martin A, Egeberg A, Wu JJ. Prevalence of psoriasis among adults in the US 2009-2010 and 2013-2014 National Health and Nutrition Examination Surveys. J Am Acad Dermatol. 2021;84(3):767-9. https://doi.org/10.1016/j.jaad. 2020.10.035.
8. Talotta R, Atzeni F, Sarzi-Puttini P, Masala IF. Psoriatic arthritis: from pathogenesis to pharmacologic management. Pharmacol Res. 2019;148:104394.

9. Alinaghi F, Calov M, Kristensen LE, Gladman DD, Coates LC, Jullien D, et al. Prevalence of psoriatic arthritis in patients with psoriasis: a systematic review and meta-analysis of observational and clinical studies. J Am Acad Dermatol. 2019;80(1):251-65. e19.

10. Schemoul J, Poulain C, Claudepierre P. Treatment strategies for psoriatic arthritis. Joint Bone Spine. 2018;85(5):537-44.

11. Mease PJ, Smolen JS, Behrens F, Nash P, Liu Leage S, Li L, et al. A head-to-head comparison of the efficacy and safety of ixekizumab and adalimumab in biological-naive patients with active psoriatic arthritis: 24-week results of a randomised, open-label, blinded-assessor trial. Ann Rheum Dis. 2020;79(1):123-31.

12. Smolen JS, Mease P, Tahir H, Schulze-Koops H, de la Torre I, Li L, et al. Multicentre, randomised, open-label, parallel-group study evaluating the efficacy and safety of ixekizumab versus adalimumab in patients with psoriatic arthritis naïve to biological disease-modifying antirheumatic drug: final results by week 52 . Ann Rheum Dis. 2020;79(10):1310-9.

13. Gottlieb AB, Strand V, Kishimoto M, Mease P, Thaci D, Birt J, et al. Ixekizumab improves patient-reported outcomes up to 52 weeks in bDMARD-naive patients with active psoriatic arthritis (SPIRIT-P1). Rheumatol (Oxf). 2018;57(10):1777-88.

14. Genovese MC, Combe B, Kremer JM, Tsai TF, Behrens F, Adams DH, et al. Safety and efficacy of ixekizumab in patients with PsA and previous inadequate response to TNF inhibitors: week 52 results from SPIRIT-P2. Rheumatol (Oxf). 2018;57(11):2001-11.

15. Mease P, van der Heijde D, Landewé R, Mpofu S, Rahman P, Tahir H, et al. Secukinumab improves active psoriatic arthritis symptoms and inhibits radiographic progression: primary results from the randomised, double-blind, phase III FUTURE 5 study. Ann Rheum Dis. 2018;77(6):890-7.

16. van der Heijde D, Mease PJ, Landewe RBM, Rahman P, Tahir $\mathrm{H}$, Singhal A, et al. Secukinumab provides sustained low rates of radiographic progression in psoriatic arthritis: 52-week results from a phase 3 study, FUTURE 5. Rheumatol (Oxf). 2020;59(6):1325-34.

17. Kavanaugh A, Mease PJ, Reimold AM, Tahir H, Rech J, Hall S, et al. Secukinumab for long-term treatment of psoriatic arthritis: a two-year followup from a phase III, randomized, doubleblind placebo-controlled study. Arthritis Care Res (Hoboken). 2017;69(3):347-55.

18. Mease PJ, Kavanaugh A, Reimold A, Tahir H, Rech J, Hall S, et al. Secukinumab in the treatment of psoriatic arthritis: efficacy and safety results through 3 years from the year 1 extension of the randomised phase III FUTURE 1 trial. RMD Open. 2018;4(2): 0000723 .

19. McInnes IB, Behrens F, Mease PJ, Kavanaugh A, Ritchlin C, Nash P, et al. Secukinumab versus adalimumab for treatment of active psoriatic arthritis (EXCEED): a double-blind, parallelgroup, randomised, active-controlled, phase $3 \mathrm{~b}$ trial. Lancet. 2020;395(10235):1496-505.

20. McInnes IB, Chakravarty SD, Apaolaza I, Kafka S, Hsia EC, You Y, et al. Efficacy of ustekinumab in biologic-naive patients with psoriatic arthritis by prior treatment exposure and disease duration: data from PSUMMIT 1 and PSUMMIT 2. RMD Open. 2019;5(2):e000990.

21. Iannone F, Santo L, Bucci R, Semeraro A, Carlino G, Paoletti F, et al. Drug survival and effectiveness of ustekinumab in patients with psoriatic arthritis. Real-life data from the biologic Apulian registry (BIOPURE). Clin Rheumatol. 2018;37(3):667-75.

22. Deodhar A, Helliwell PS, Boehncke WH, Kollmeier AP, Hsia EC, Subramanian RA, et al. Guselkumab in patients with active 
psoriatic arthritis who were biologic-naive or had previously received TNFalpha inhibitor treatment (DISCOVER-1): a double-blind, randomised, placebo-controlled phase 3 trial. Lancet. 2020;395(10230):1115-25.

23. Mease PJ, Gladman DD, Deodhar A, McGonagle DG, Nash P, Boehncke WH, et al. Impact of guselkumab, an interleukin-23 p19 subunit inhibitor, on enthesitis and dactylitis in patients with moderate to severe psoriatic arthritis: results from a randomised, placebo-controlled, phase II study. RMD Open. 2020;6:2.

24. Deodhar A, Helliwell PS, Boehncke WH, Kollmeier AP, Hsia EC, Subramanian RA, et al. Guselkumab in patients with active psoriatic arthritis who were biologic-naive or had previously received TNF $\alpha$ inhibitor treatment (DISCOVER-1): a doubleblind, randomised, placebo-controlled phase 3 trial. Lancet. 2020;395(10230):1115-25.

25. Mease PJ, Rahman P, Gottlieb AB, Kollmeier AP, Hsia EC, Xu $\mathrm{XL}$, et al. Guselkumab in biologic-naive patients with active psoriatic arthritis (DISCOVER-2): a double-blind, randomised, placebo-controlled phase 3 trial. Lancet. 2020;395(10230):1126-36.

26. D'Angelo S, Tramontano G, Gilio M, Leccese P, Olivieri I. Review of the treatment of psoriatic arthritis with biological agents: choice of drug for initial therapy and switch therapy for non-responders. Open Access Rheumatol. 2017;9:21-8.

27. Singh JA, Guyatt G, Ogdie A, Gladman DD, Deal C, Deodhar A, et al. Special article: 2018 American College of Rheumatology/National psoriasis foundation guideline for the treatment of psoriatic arthritis. Arthritis Rheumatol. 2019;71(1):5-32.

28. Janssen Biotech Inc. Tremfya (guselkumab): for less joint pain, stiffness, and swelling at 24 weeks. 2017. https://www.tremfya. com/psoriatic-arthritis. Accessed 5 Sep 2020.

29. Ruiz-de-Morales JMG, Puig L, Dauden E, Canete JD, Pablos JL, Martin AO, et al. Critical role of interleukin (IL)-17 in inflammatory and immune disorders: an updated review of the evidence focusing in controversies. Autoimmun Rev. 2020;19(1):102429.

30. Chohan S, Kavanaugh A, Strand V, Chou RC, Mendelsohn AM, Rozzo S, et al. AB0803 Efficacy of tildrakizumab in PsA: DAS28-CRP scores through week 52. Ann Rheum Dis. 2020;79(Suppl 1):1702-3.

31. Silfvast-Kaiser AS, Homan KB, Mansouri B. A narrative review of psoriasis and multiple sclerosis: links and risks. Psoriasis (Auckl). 2019;9:81-90.

32. Egeberg A, Mallbris L, Gislason GH, Skov L, Hansen PR. Risk of multiple sclerosis in patients with psoriasis: a Danish Nationwide Cohort Study. J Invest Dermatol. 2016;136(1):93-8.

33. Gieler U. Psoriasis and multiple sclerosis—hidden link? J Eur Acad Dermatol Venereol. 2017;31(12):1949.

34. Mansouri B, Horner ME, Menter A. Tumor necrosis factor- $\alpha$ inhibitor use in psoriasis patients with a first-degree relative with multiple sclerosis. J Drugs Dermatol. 2015;14(8):876-8.

35. Di Tullio F, Odorici G, Lasagni C, Capobianco M, Conti A, Mandel VD. Combination treatment with secukinumab and dimethyl fumarate in a patient with psoriasis and recent diagnosis of multiple sclerosis. Dermatol Ther. 2020;2:e13943.

36. Seror R, Richez C, Sordet C, Rist S, Gossec L, Direz G, et al. Pattern of demyelination occurring during anti-TNF- $\alpha$ therapy: a French national survey. Rheumatol (Oxf). 2013;52(5):868-74.

37. Dreyer L, Magyari M, Laursen B, Cordtz R, Sellebjerg F, Locht $\mathrm{H}$. Risk of multiple sclerosis during tumour necrosis factor inhibitor treatment for arthritis: a population-based study from DANBIO and the Danish Multiple Sclerosis Registry. Ann Rheum Dis. 2016;75(4):785-6.

38. Kunchok A, Aksamit AJ Jr, Davis JM 3rd, Kantarci OH, Keegan BM, Pittock SJ, et al. Association between tumor necrosis factor inhibitor exposure and inflammatory central nervous system events. JAMA Neurol. 2020;77(8):937-46.
39. Andersen NN, Caspersen S, Jess T, Munkholm P. Occurrence of demyelinating diseases after anti-TNF $\alpha$ treatment of inflammatory bowel disease: a Danish Crohn Colitis Database study. J Crohns Colitis. 2008;2(4):304-9.

40. Lozeron P, Denier C, Lacroix C, Adams D. Long-term course of demyelinating neuropathies occurring during tumor necrosis factor-alpha-blocker therapy. Arch Neurol. 2009;66(4):490-7.

41. Fromont A, De Seze J, Fleury MC, Maillefert JF, Moreau T. Inflammatory demyelinating events following treatment with anti-tumor necrosis factor. Cytokine. 2009;45(2):55-7.

42. Havrdová E, Belova A, Goloborodko A, Tisserant A, Wright A, Wallstroem E, et al. Activity of secukinumab, an anti-IL-17A antibody, on brain lesions in RRMS: results from a randomized, proof-of-concept study. J Neurol. 2016;263(7):1287-95.

43. Diebold M, Müller S, Derfuss T, Décard BF. A case of concomitant psoriasis and multiple sclerosis: secukinumab and rituximab exert dichotomous effects in two autoimmune conditions. Mult Scler Relat Disord. 2019;31:38-40.

44. Assefa GT, Kaneko S, Oguro H, Morita E. Treatment of psoriasis and psoriatic arthritis with secukinumab after unsatisfactory response to ustekinumab in multiple sclerosis patient. J Dermatol. 2019;46(3):e112-3.

45. Megna M, Marasca C, Ruggiero A, Camela E, Fabbrocini G. Secukinumab: a potential safe option in psoriasis patients affected by multiple sclerosis? Int J Dermatol. 2020;59(8):e308-9.

46. Venturini M, Zanca A, Venturuzzo A, Filippini M, Frassi M, Tincani A, et al. Secukinumab for patients with plaque psoriasis affected by multiple sclerosis: a mini-review with a representative case report. J Eur Acad Dermatol Venereol. 2020;34(2):e110-2.

47. Segal BM, Constantinescu CS, Raychaudhuri A, Kim L, Fidelus-Gort R, Kasper LH. Repeated subcutaneous injections of IL12/23 p40 neutralising antibody, ustekinumab, in patients with relapsing-remitting multiple sclerosis: a phase II, double-blind, placebo-controlled, randomised, dose-ranging study. Lancet Neurol. 2008;7(9):796-804.

48. Leonardi CL, Kimball AB, Papp KA, Yeilding N, Guzzo C, Wang Y, et al. Efficacy and safety of ustekinumab, a human interleukin-12/23 monoclonal antibody, in patients with psoriasis: 76-week results from a randomised, double-blind, placebocontrolled trial (PHOENIX 1). Lancet. 2008;371(9625):1665-74.

49. Papp KA, Griffiths CE, Gordon K, Lebwohl M, Szapary PO, Wasfi Y, et al. Long-term safety of ustekinumab in patients with moderate-to-severe psoriasis: final results from 5 years of followup. Br J Dermatol. 2013;168(4):844-54.

50. Kapizioni C, Makris K, Kourkoulis P, Vrakas S, Michalopoulos G. Is Ustekinumab the best treatment option in patients with Crohn's disease and coexistent multiple sclerosis? Acta Gastroenterol Belg. 2019;82(2):337.

51. Chang S, Chambers CJ, Liu FT, Armstrong AW. Successful treatment of psoriasis with ustekinumab in patients with multiple sclerosis. Dermatol Online J. 2015;21:7.

52. Blauvelt A, Reich K, Papp KA, Kimball AB, Gooderham M, Tyring SK, et al. Safety of tildrakizumab for moderate-to-severe plaque psoriasis: pooled analysis of three randomized controlled trials. Br J Dermatol. 2018;179(3):615-22.

53. Gordon KB, Strober B, Lebwohl M, Augustin M, Blauvelt A, Poulin Y, et al. Efficacy and safety of risankizumab in moderate-to-severe plaque psoriasis (UltIMMa-1 and UltIMMa-2): results from two double-blind, randomised, placebo-controlled and ustekinumab-controlled phase 3 trials. Lancet. 2018;392(10148):650-61.

54. Reich K, Armstrong AW, Foley P, Song M, Wasfi Y, Randazzo $\mathrm{B}$, et al. Efficacy and safety of guselkumab, an anti-interleukin-23 monoclonal antibody, compared with adalimumab for the treatment of patients with moderate to severe psoriasis with randomized withdrawal and retreatment: Results from the phase III, 
double-blind, placebo- and active comparator-controlled VOYAGE 2 trial. J Am Acad Dermatol. 2017;76(3):418-31.

55. Langley RG, Tsai TF, Flavin S, Song M, Randazzo B, Wasfi Y, et al. Efficacy and safety of guselkumab in patients with psoriasis who have an inadequate response to ustekinumab: results of the randomized, double-blind, phase III NAVIGATE trial. Br J Dermatol. 2018;178(1):114-23.

56. Blauvelt A, Papp KA, Griffiths CE, Randazzo B, Wasfi Y, Shen YK, et al. Efficacy and safety of guselkumab, an anti-interleukin-23 monoclonal antibody, compared with adalimumab for the continuous treatment of patients with moderate to severe psoriasis: results from the phase III, double-blinded, placeboand active comparator-controlled VOYAGE 1 trial. J Am Acad Dermatol. 2017;76(3):405-17.

57. Khalid U, Ahlehoff O, Gislason GH, Kristensen SL, Skov L, Torp-Pedersen $\mathrm{C}$, et al. Psoriasis and risk of heart failure: a nationwide cohort study. Eur J Heart Fail. 2014;16(7):743-8.

58. Hugh J, Van Voorhees AS, Nijhawan RI, Bagel J, Lebwohl M, Blauvelt A, et al. From the Medical Board of the National Psoriasis Foundation: the risk of cardiovascular disease in individuals with psoriasis and the potential impact of current therapies. J Am Acad Dermatol. 2014;70(1):168-77.

59. Heslinga SC, Van Sijl AM, De Boer K, Van Halm VP, Nurmohamed MT. Tumor necrosis factor blocking therapy and congestive heart failure in patients with inflammatory rheumatic disorders: a systematic review. Curr Med Chem. 2015;22(16):1892-902.

60. Puig L. Cardiovascular risk and psoriasis: the role of biologic therapy. Actas Dermosifiliogr. 2012;103(10):853-62.

61. Boyer JF, Jamard B, El Mahou S, Laroche M, Mazières B, Cantagrel A, et al. New-onset acute heart failure and ventricular tachycardia after therapy with a tumor necrosis factor antagonist. Clin Exp Rheumatol. 2005;23(2):274-5.

62. Caiazzo G, Fabbrocini G, Di Caprio R, Raimondo A, Scala E, Balato N, et al. Psoriasis, cardiovascular events, and biologics: lights and shadows. Front Immunol. 2018;9:1668.

63. Kwon HJ, Coté TR, Cuffe MS, Kramer JM, Braun MM. Case reports of heart failure after therapy with a tumor necrosis factor antagonist. Ann Intern Med. 2003;138(10):807-11.

64. Chung ES, Packer M, Lo KH, Fasanmade AA, Willerson JT. Randomized, double-blind, placebo-controlled, pilot trial of infliximab, a chimeric monoclonal antibody to tumor necrosis factor-alpha, in patients with moderate-to-severe heart failure: results of the anti-TNF Therapy Against Congestive Heart Failure (ATTACH) trial. Circulation. 2003;107(25):3133-40.

65. Desai SB, Furst DE. Problems encountered during anti-tumour necrosis factor therapy. Best Pract Res Clin Rheumatol. 2006;20(4):757-90.

66. Menter A, Gottlieb A, Feldman SR, Van Voorhees AS, Leonardi $\mathrm{CL}$, Gordon KB, et al. Guidelines of care for the management of psoriasis and psoriatic arthritis: section 1. Overview of psoriasis and guidelines of care for the treatment of psoriasis with biologics. J Am Acad Dermatol. 2008;58(5):826-50.

67. Lebwohl MG, Blauvelt A, Menter A, Papp KA, Guenthner S, Pillai R, et al. Efficacy, safety, and patient-reported outcomes in patients with moderate-to-severe plaque psoriasis treated with brodalumab for 5 years in a long-term, open-label, phase II study. Am J Clin Dermatol. 2019;20(6):863-71.

68. Strober BE, Germino R, Guana A, Greenberg JD, Litman HJ, Guo N, et al. US real-world effectiveness of secukinumab for the treatment of psoriasis: 6-month analysis from the Corrona Psoriasis Registry. J Dermatolog Treat. 2020;31(4):333-41.

69. Blauvelt A, Gooderham M, Iversen L, Ball S, Zhang L, Agada $\mathrm{NO}$, et al. Efficacy and safety of ixekizumab for the treatment of moderate-to-severe plaque psoriasis: results through 108 weeks of a randomized, controlled phase 3 clinical trial (UNCOVER-3). J Am Acad Dermatol. 2017;77(5):855-62.

70. Gordon KB, Blauvelt A, Papp KA, Langley RG, Luger T, Ohtsuki $\mathrm{M}$, et al. Phase 3 trials of ixekizumab in moderate-to-severe plaque psoriasis. N Engl J Med. 2016;375(4):345-56.

71. Kimball AB, Gordon KB, Fakharzadeh S, Yeilding N, Szapary PO, Schenkel B, et al. Long-term efficacy of ustekinumab in patients with moderate-to-severe psoriasis: results from the PHOENIX 1 trial through up to 3 years. Br J Dermatol. 2012;166(4):861-72.

72. Langley RG, Lebwohl M, Krueger GG, Szapary PO, Wasfi Y, Chan D, et al. Long-term efficacy and safety of ustekinumab, with and without dosing adjustment, in patients with moderateto-severe psoriasis: results from the PHOENIX 2 study through 5 years of follow-up. Br J Dermatol. 2015;172(5):1371-83.

73. Champs B, Degboé Y, Barnetche T, Cantagrel A, RuyssenWitrand A, Constantin A. Short-term risk of major adverse cardiovascular events or congestive heart failure in patients with psoriatic arthritis or psoriasis initiating a biological therapy: a meta-analysis of randomised controlled trials. RMD Open. 2019;5(1):e000763.

74. Egeberg A, Thyssen JP, Burisch J, Colombel JF. Incidence and risk of inflammatory bowel disease in patients with psoriasis-a nationwide 20-year cohort study. J Invest Dermatol. 2019;139(2):316-23.

75. Whitlock SM, Enos CW, Armstrong AW, Gottlieb A, Langley RG, Lebwohl M, et al. Management of psoriasis in patients with inflammatory bowel disease: From the Medical Board of the National Psoriasis Foundation. J Am Acad Dermatol. 2018;78(2):383-94.

76. Kawalec P, Mikrut A, Wiśniewska N, Pilc A. Tumor necrosis factor- $\alpha$ antibodies (infliximab, adalimumab and certolizumab) in Crohn's disease: systematic review and meta-analysis. Arch Med Sci. 2013;9(5):765-79.

77. Korzenik J, Larsen MD, Nielsen J, Kjeldsen J, Nørgård BM. Increased risk of developing Crohn's disease or ulcerative colitis in 17018 patients while under treatment with anti-TNF $\alpha$ agents, particularly etanercept, for autoimmune diseases other than inflammatory bowel disease. Aliment Pharmacol Ther. 2019;50(3):289-94.

78. Pouillon L, Baumann C, Rousseau H, Choukour M, Andrianjafy C, Danese S, et al. Treatment persistence of infliximab versus adalimumab in ulcerative colitis: a 16-year single-center experience. Inflamm Bowel Dis. 2019;25(5):945-54.

79. Olivera P, Thiriet L, Luc A, Baumann C, Danese S, Peyrin-Biroulet $\mathrm{L}$. Treatment persistence for infliximab versus adalimumab in Crohn's disease: a 14-year single-center experience. Inflamm Bowel Dis. 2017;23(6):976-85.

80. Colombel JF, Sandborn WJ, Reinisch W, Mantzaris GJ, Kornbluth A, Rachmilewitz D, et al. Infliximab, azathioprine, or combination therapy for Crohn's disease. N Engl J Med. 2010;362(15):1383-95.

81. Hanauer S, Sandborn WJ, Colombel JF, Vermeire S, Petersson J, Kligys K, et al. Rapid changes in laboratory parameters and early response to adalimumab: a pooled analysis from patients with ulcerative colitis in two clinical trials. J Crohns Colitis. 2019;13(9):1227-33.

82. Reinisch W, Sandborn WJ, Hommes DW, D'Haens G, Hanauer $\mathrm{S}$, Schreiber S, et al. Adalimumab for induction of clinical remission in moderately to severely active ulcerative colitis: results of a randomised controlled trial. Gut. 2011;60(6):780-7.

83. O'Toole A, Lucci M, Korzenik J. Inflammatory bowel disease provoked by etanercept: report of 443 possible cases combined from an IBD referral center and the FDA. Dig Dis Sci. 2016;61(6):1772-4. 
84. Schreiber S, Colombel JF, Feagan BG, Reich K, Deodhar AA, McInnes IB, et al. Incidence rates of inflammatory bowel disease in patients with psoriasis, psoriatic arthritis and ankylosing spondylitis treated with secukinumab: a retrospective analysis of pooled data from 21 clinical trials. Ann Rheum Dis. 2019;78(4):473-9.

85. Reich K, Leonardi C, Langley RG, Warren RB, Bachelez H, Romiti R, et al. Inflammatory bowel disease among patients with psoriasis treated with ixekizumab: a presentation of adjudicated data from an integrated database of 7 randomized controlled and uncontrolled trials. J Am Acad Dermatol. 2017;76(3):441-8.e2.

86. Targan SR, Feagan B, Vermeire S, Panaccione R, Melmed GY, Landers $\mathrm{C}$, et al. A randomized, double-blind, placebo-controlled phase 2 study of brodalumab in patients with moderate-to-severe Crohn's disease. Am J Gastroenterol. 2016;111(11):1599-607.

87. Koo J, Ho RS, Thibodeaux Q. Depression and suicidality in psoriasis and clinical studies of brodalumab: a narrative review. Cutis. 2019;104(6):361-5.

88. Eli Lilly and Company. TALTZ (ixekizumab) injection, for subcutaneous use: US prescribing information. 2016. https://www. accessdata.fda.gov/drugsatfda_docs/label/2017/125521s004lbl. pdf. Accessed 1 Sep 2020.

89. Novartis Inc. COSENTYX® (secukinumab) injection, for subcutaneous use: US prescribing information. 2015. https://www. accessdata.fda.gov/drugsatfda_docs/label/2016/125504s001 s002lbl.pdf. Accessed 1 Oct 2020.

90. AstraZeneca Inc. SILIQTM (brodalumab) injection, for subcutaneous use. 2017. https://www.accessdata.fda.gov/drugsatfda_ docs/label/2017/761032lbl.pdf. Accessed 23 Sep 2020.

91. Sandborn WJ, Rutgeerts P, Gasink C, Jacobstein D, Zou B, Johanns J, et al. Long-term efficacy and safety of ustekinumab for Crohn's disease through the second year of therapy. Aliment Pharmacol Ther. 2018;48(1):65-77.

92. Rutgeerts P, Gasink C, Chan D, Lang Y, Pollack P, Colombel JF, et al. Efficacy of ustekinumab for inducing endoscopic healing in patients with Crohn's disease. Gastroenterology. 2018;155(4):1045-58.

93. Ahmed Z, Venkata K, Zhang N, Malik TA. Comparative effectiveness of ustekinumab versus adalimumab in induction of clinical response and remission in Crohn's disease: experience of a real-world cohort at a tertiary care inflammatory bowel disease referral center. Gastroenterol Res. 2019;12(5):245-51.

94. Sands BE, Sandborn WJ, Panaccione R, O'Brien CD, Zhang H, Johanns J, et al. Ustekinumab as induction and maintenance therapy for ulcerative colitis. N Engl J Med. 2019;381(13):1201-14.

95. Warren RB, Blauvelt A, Poulin Y, et al. Efficacy and safety of risankizumab vs. secukinumab in patients with moderate-tosevere plaque psoriasis (IMMerge): results from a phase III, randomized, open-label, efficacy-assessor-blinded clinical trial. Br J Dermatol. 2021;184(1):50-9. https://doi.org/10.1111/bjd. 19341.

96. Reich K, Gooderham M, Thaçi D, Crowley JJ, Ryan C, Krueger JG, et al. Risankizumab compared with adalimumab in patients with moderate-to-severe plaque psoriasis (IMMvent): a randomised, double-blind, active-comparator-controlled phase 3 trial. Lancet. 2019;394(10198):576-86.

97. Reich K, Armstrong AW, Langley RG, Flavin S, Randazzo B, $\mathrm{Li}$ S, et al. Guselkumab versus secukinumab for the treatment of moderate-to-severe psoriasis (ECLIPSE): results from a phase 3, randomised controlled trial. Lancet. 2019;394(10201):831-9.

98. Fieldhouse KA, Ukaibe S, Crowley EL, Khanna R, O'Toole A, Gooderham MJ. Inflammatory bowel disease in patients with psoriasis treated with interleukin-17 inhibitors. Drugs Context. 2020;2020:9.

99. Hedley-Whyte J, Milamed DR. Hepatitis B: prevalence, hope. Ulster Med J. 2019;88(2):118-23.
100. Fung J, Lai CL, Yuen MF. Management of chronic hepatitis B in severe liver disease. World J Gastroenterol. 2014;20(43):16053-61.

101. Centers for Disease Control and Prevention. Hepatitis B information for health professionals. 2020. https://www.cdc.gov/hepat itis/hbv/index.htm. Accessed 29 Sep 2020.

102. Piaserico S, Messina F, Russo FP. Managing psoriasis in patients with $\mathrm{HBV}$ or $\mathrm{HCV}$ infection: practical considerations. Am J Clin Dermatol. 2019;20(6):829-45.

103. Kaushik SB, Lebwohl MG. Psoriasis: which therapy for which patient: focus on special populations and chronic infections. J Am Acad Dermatol. 2019;80(1):43-53.

104. Chiu HY, Chiu YM, Chang Liao NF, et al. Predictors of hepatitis $\mathrm{B}$ and $\mathrm{C}$ virus reactivation in patients with psoriasis treated with biological agent: a nine-year multicenter cohort study. J Am Acad Dermatol. 2019;S0190-9622(19)33209-8. https://doi.org/ 10.1016/j.jaad.2019.12.001.

105. Snast I, Atzmony L, Braun M, Hodak E, Pavlovsky L. Risk for hepatitis $\mathrm{B}$ and $\mathrm{C}$ virus reactivation in patients with psoriasis on biologic therapies: a retrospective cohort study and systematic review of the literature. J Am Acad Dermatol. 2017;77(1):88-97. e5.

106. Lebwohl M, Leonardi C, Wu JJ, Yamauchi P, Rawnsley N, Merchant $\mathrm{M}$, et al. One-year pharmacovigilance update of brodalumab. J Drugs Dermatol. 2020;19(8):807-8.

107. Chiu HY, Hui RC, Huang YH, Huang RY, Chen KL, Tsai YC, et al. Safety profile of secukinumab in treatment of patients with psoriasis and concurrent hepatitis B or C: a multicentric prospective cohort study. Acta Derm Venereol. 2018;98(9):829-34.

108. Ting SW, Chen YC, Huang YH. Risk of hepatitis B reactivation in patients with psoriasis on ustekinumab. Clin Drug Investig. 2018;38(9):873-80.

109. Chiu HY, Chen CH, Wu MS, Cheng YP, Tsai TF. The safety profile of ustekinumab in the treatment of patients with psoriasis and concurrent hepatitis B or C. Br J Dermatol. 2013;169(6):1295-303.

110. Siegel SAR, Winthrop KL, Ehst BD, Ortega LA. Ustekinumab use in patients with severe psoriasis co-infected with hepatitis B and/or C. Br J Dermatol. 2019;180(5):1232-3.

111. Janssen Biotech Inc. TremfyaTM (guselkumab) injection, for subcutaneous use: US prescribing information. 2017. https:// www.accessdata.fda.gov/drugsatfda_docs/label/2017/76106 1s000lbl.pdf. Accessed 1 Sep 2020.

112. Abbvie Inc. SKYRIZITM (risankizumab-rzaa) injection, for subcutaneous use: US prescribing information. 2019. https://www. accessdata.fda.gov/drugsatfda_docs/label/2019/761105s000lbl. pdf. Accessed 1 Sep 2020.

113. Sun Pharma Inc. ILUMYATM (tildrakizumab-asmn) injection, for subcutaneous use: US perscribing information. 2018. https:// www.accessdata.fda.gov/drugsatfda_docs/label/2018/76106 7s000lbl.pdf\#page $=10$. Accessed 1 Sep 2020.

114. Reich K, Warren RB, Iversen L, Puig L, Pau-Charles I, Igarashi A, et al. Long-term efficacy and safety of tildrakizumab for moderate-to-severe psoriasis: pooled analyses of two randomized phase III clinical trials (reSURFACE 1 and reSURFACE 2) through 148 weeks. Br J Dermatol. 2020;182(3):605-17.

115. Motaparthi K, Stanisic V, Van Voorhees AS, Lebwohl MG, Hsu S. From the Medical Board of the National Psoriasis Foundation: Recommendations for screening for hepatitis B infection prior to initiating anti-tumor necrosis factor-alfa inhibitors or other immunosuppressive agents in patients with psoriasis. J Am Acad Dermatol. 2014;70(1):178-86.

116. Centers for Disease Control and Prevention. Interpretation of Hepatitis B Serologic Test Results. 2020. https://www.cdc.gov/ hepatitis/hbv/pdfs/SerologicChartv8.pdf. Accessed 15 Sep 2020. 
117. Mori S, Fujiyama S. Hepatitis B virus reactivation associated with antirheumatic therapy: risk and prophylaxis recommendations. World J Gastroenterol. 2015;21(36):10274-89.

118. Cantini F, Nannini C, Niccoli L, Iannone F, Delogu G, Garlaschi G, et al. Guidance for the management of patients with latent tuberculosis infection requiring biologic therapy in rheumatology and dermatology clinical practice. Autoimmun Rev. 2015;14(6):503-9.

119. Doherty SD, Van Voorhees A, Lebwohl MG, Korman NJ, Young MS, Hsu S, et al. National Psoriasis Foundation consensus statement on screening for latent tuberculosis infection in patients with psoriasis treated with systemic and biologic agents. J Am Acad Dermatol. 2008;59(2):209-17.

120. Soare A, Gheorghiu AM, Aramă V, Bumbăcea D, Dobrotă R, Oneaţă R, et al. Risk of active tuberculosis in patients with inflammatory arthritis receiving TNF inhibitors: a look beyond the baseline tuberculosis screening protocol. Clin Rheumatol. 2018;37(9):2391-7.

121. Lalvani A, Millington KA. Screening for tuberculosis infection prior to initiation of anti-TNF therapy. Autoimmun Rev. 2008;8(2):147-52.

122. Chen YH, de Carvalho HM, Kalyoncu U, Llamado LJQ, Solano $\mathrm{G}$, Pedersen R, et al. Tuberculosis and viral hepatitis infection in Eastern Europe, Asia, and Latin America: impact of tumor necrosis factor- $\alpha$ inhibitors in clinical practice. Biologics. 2018;12:1-9.

123. US Food and Drug Administration. FDA Drug Safety Communication: Drug labels for the Tumor Necrosis Factor-alpha (TNF\&alpha;) blockers now include warnings about infection with Legionella and Listeria bacteria. 2017. https://www.fda.gov/ drugs/drug-safety-and-availability/fda-drug-safety-communicat ion-drug-labels-tumor-necrosis-factor-alpha-tnfa-blockers-nowinclude. Accessed 17 Sep 2020.

124. Baddley JW, Cantini F, Goletti D, Gómez-Reino JJ, Mylonakis E, San-Juan R, et al. ESCMID Study Group for Infections in Compromised Hosts (ESGICH) Consensus Document on the safety of targeted and biological therapies: an infectious diseases perspective (Soluble immune effector molecules [I]: anti-tumor necrosis factor- $\alpha$ agents). Clin Microbiol Infect. 2018;24(Suppl 2):S10-s20.

125. Curtis JR, Mariette X, Gaujoux-Viala C, Blauvelt A, Kvien TK, Sandborn WJ, et al. Long-term safety of certolizumab pegol in rheumatoid arthritis, axial spondyloarthritis, psoriatic arthritis, psoriasis and Crohn's disease: a pooled analysis of 11,317 patients across clinical trials. RMD Open. 2019;5(1):e000942.

126. Zhang Z, Fan W, Yang G, Xu Z, Wang J, Cheng Q, et al. Risk of tuberculosis in patients treated with TNF- $\alpha$ antagonists: a systematic review and meta-analysis of randomised controlled trials. BMJ Open. 2017;7(3):e012567.

127. Menter A, Thaçi D, Wu JJ, Abramovits W, Kerdel F, Arikan $\mathrm{D}$, et al. Long-term safety and effectiveness of adalimumab for moderate to severe psoriasis: results from 7-year interim analysis of the ESPRIT registry. Dermatol Ther (Heidelb). 2017;7(3):365-81.

128. Leonardi C, Papp K, Strober B, Thaçi D, Warren RB, Tyring S, et al. Comprehensive long-term safety of adalimumab from 18 clinical trials in adult patients with moderate-to-severe plaque psoriasis. Br J Dermatol. 2019;180(1):76-85.

129. Burmester GR, Gordon KB, Rosenbaum JT, Arikan D, Lau WL, Li P, et al. Long-term safety of adalimumab in 29,967 adult patients from global clinical trials across multiple indications: an updated analysis. Adv Ther. 2020;37(1):364-80.

130. Keane J, Gershon S, Wise RP, Mirabile-Levens E, Kasznica J, Schwieterman WD, et al. Tuberculosis associated with infliximab, a tumor necrosis factor alpha-neutralizing agent. $\mathrm{N}$ Engl $\mathrm{J}$ Med. 2001;345(15):1098-104.
131. Armstrong A, Paul C, Puig L, Boehncke WH, Freeman M, Torii $\mathrm{H}$, et al. Safety of ixekizumab treatment for up to 5 years in adult patients with moderate-to-severe psoriasis: results from greater than 17,000 patient-years of exposure. Dermatol Ther (Heidelb). 2020;10(1):133-50.

132. Kammüller M, Tsai TF, Griffiths CE, Kapoor N, Kolattukudy PE, Brees D, et al. Inhibition of IL-17A by secukinumab shows no evidence of increased mycobacterium tuberculosis infections. Clin Transl Immunol. 2017;6(8):e152.

133. van de Kerkhof PC, Griffiths CE, Reich K, Leonardi CL, Blauvelt A, Tsai TF, et al. Secukinumab long-term safety experience: a pooled analysis of 10 phase II and III clinical studies in patients with moderate to severe plaque psoriasis. J Am Acad Dermatol. 2016;75(1):83-98.e4.

134. Tsai TF, Ho V, Song M, Szapary P, Kato T, Wasfi Y, et al. The safety of ustekinumab treatment in patients with moderate-tosevere psoriasis and latent tuberculosis infection. Br J Dermatol. 2012;167(5):1145-52.

135. Puig L, Tsai TF, Bhutani T, Uy J, Ramachandran P, Song M, et al. Safety in moderate-to-severe plaque psoriasis patients with latent tuberculosis treated with guselkumab and anti-tuberculosis treatments concomitantly: results from pooled phase 3 VOYAGE 1 \& VOYAGE 2 trials. J Eur Acad Dermatol Venereol. 2020;34(8):1744-9.

136. AbbVie Inc. HUMIRA $®$ (adalimumab) injection, for subcutaneous use: US prescribing information. 2018. https://www.acces sdata.fda.gov/drugsatfda_docs/label/2018/125057s410lbl.pdf. Accessed 23 Sept 2020.

137. UCB Inc. CIMZIA (certolizumab pegol) for injection, for subcutaneous use: US prescribing information. 2017. https://www. accessdata.fda.gov/drugsatfda_docs/label/2017/125160s270lbl. pdf. Accessed 2 Oct 2020.

138. Janssen Biotech I. STELARA® (ustekinumab) injection, for subcutaneous or intravenous use. 2017. https://www.accessdata.fda. gov/drugsatfda_docs/label/2016/761044lbl.pdf. Accessed 20 Sep 2020.

139. Amgen. ENBREL $®$ (etanercept) injection, for subcutaneous use: US prescribing information. 1998. https://www.accessdata.fda. gov/drugsatfda_docs/label/2012/103795s5503lbl.pdf. Accessed 15 Sep 2020.

140. Janssen Biotech. REMICADE (infliximab) Lyophilized Concentrate for Injection, for Intravenous Use: US prescribing information. 2013. https://www.accessdata.fda.gov/drugsatfda_docs/ label/2013/103772s5359lbl.pdf. Accessed 29 Sep 2020.

141. Eichenfield LF, Paller AS, Tom WL, Sugarman J, Hebert AA, Friedlander SF, et al. Pediatric psoriasis: evolving perspectives. Pediatr Dermatol. 2018;35(2):170-81.

142. Lansang P, Bergman JN, Fiorillo L, Joseph M, Lara-Corrales I, Marcoux D, et al. Management of pediatric plaque psoriasis using biologics. J Am Acad Dermatol. 2020;82(1):213-21.

143. Di Lernia V, Guarneri C, Stingeni L, Gisondi P, Bonamonte D, Calzavara Pinton PG, et al. Effectiveness of etanercept in children with plaque psoriasis in real practice: a one-year multicenter retrospective study. J Dermatolog Treat. 2018;29(3):217-9.

144. Paller AS, Siegfried EC, Pariser DM, Rice KC, Trivedi M, Iles $\mathrm{J}$, et al. Long-term safety and efficacy of etanercept in children and adolescents with plaque psoriasis. J Am Acad Dermatol. 2016;74(2):280-7.

145. Paller AS, Siegfried EC, Langley RG, Gottlieb AB, Pariser D, Landells I, et al. Etanercept treatment for children and adolescents with plaque psoriasis. N Engl J Med. 2008;358(3):241-51.

146. Phan C, Beauchet A, Burztejn AC, Severino-Freire M, Barbarot $\mathrm{S}$, Girard C, et al. Biological treatments for paediatric psoriasis : a retrospective observational study on biological drug survival in daily practice in childhood psoriasis. J Eur Acad Dermatol Venereol. 2019;33(10):1984-92. 
147. Papp K, Thaçi D, Marcoux D, Weibel L, Philipp S, Ghislain PD, et al. Efficacy and safety of adalimumab every other week versus methotrexate once weekly in children and adolescents with severe chronic plaque psoriasis: a randomised, double-blind, phase 3 trial. Lancet. 2017;390(10089):40-9.

148. Paller AS, Seyger MMB, Alejandro Magariños G, Bagel J, Pinter A, Cather J, et al. Efficacy and safety of ixekizumab in a phase III, randomized, double-blind, placebo-controlled study in paediatric patients with moderate-to-severe plaque psoriasis (IXORAPEDS). Br J Dermatol. 2020;183(2):231-41.

149. Landells I, Marano C, Hsu MC, Li S, Zhu Y, Eichenfield LF, et al. Ustekinumab in adolescent patients age 12 to 17 years with moderate-to-severe plaque psoriasis: results of the randomized phase 3 CADMUS study. J Am Acad Dermatol. 2015;73(4):594-603.

150. Philipp S, Menter A, Nikkels AF, Barber K, Landells I, Eichenfield LF, et al. Ustekinumab for the treatment of moderateto-severe plaque psoriasis in paediatric patients ( $\geq 6$ to $<12$ years of age): efficacy, safety, pharmacokinetic and biomarker results from the open-label CADMUS Jr study. Br J Dermatol. 2020;183(4):664-72.

151. Novartis I. Novartis Cosentyx ${ }^{\circledR}$ receives EU approval for firstline systemic treatment in pediatric psoriasis. 2020. https://www. novartis.com/news/media-releases/novartis-cosentyx-receiveseu-approval-first-line-systemic-treatment-pediatric-psoriasis. Accessed 9 Mar 2021.

152. De Simone C, Caldarola G, Moretta G, Piscitelli L, Ricceri F, Prignano F. Moderate-to-severe psoriasis and pregnancy: impact on fertility, pregnancy outcome and treatment perspectives. G Ital Dermatol Venereol. 2019;154(3):305-14.

153. Galluzzo M, D’Adamio S, Bianchi L, Talamonti M. Psoriasis in pregnancy: case series and literature review of data concerning exposure during pregnancy to ustekinumab. J Dermatolog Treat. 2019;30(1):40-4.

154. Ferreira C, Azevedo A, Nogueira M, Torres T. Management of psoriasis in pregnancy - a review of the evidence to date. Drugs Context. 2020;2020:9.

155. Góralczyk A, Kolossa K, Waszczak-Jeka M, Adamczak R, Jeka $\mathrm{S}$. The exposure to biologic and targeted synthetic disease-modifying antirheumatic drugs in pregnancy and lactation. Postepy Dermatol Alergol. 2020;37(3):306-12.

156. Bröms G, Kieler H, Ekbom A, Gissler M, Hellgren K, Lahesmaa-Korpinen AM, et al. Anti-TNF treatment during pregnancy and birth outcomes: a population-based study from Denmark, Finland, and Sweden. Pharmacoepidemiol Drug Saf. 2020;29(3):316-27.

157. Geldhof A, Slater J, Clark M, Chandran U, Coppola D. Exposure to infliximab during pregnancy: post-marketing experience. Drug Saf. 2020;43(2):147-61.

158. Seow CH, Nguyen GC. "Just in Time": when is it safe to administer live vaccines to infants exposed to anti-tumor necrosis factor agents in utero? Gastroenterology. 2016;151(6):1249-50.

159. Gisbert JP, Chaparro M. Safety of anti-TNF agents during pregnancy and breastfeeding in women with inflammatory bowel disease. Am J Gastroenterol. 2013;108(9):1426-38.

160. Chambers CD, Johnson DL, Xu R, Luo Y, Lopez-Jimenez J, Adam MP, et al. Birth outcomes in women who have taken adalimumab in pregnancy: a prospective cohort study. PLoS ONE. 2019;14(10):e0223603.

161. Mariette X, Förger F, Abraham B, Flynn AD, Moltó A, Flipo RM, et al. Lack of placental transfer of certolizumab pegol during pregnancy: results from CRIB, a prospective, postmarketing, pharmacokinetic study. Ann Rheum Dis. 2018;77(2):228-33.

162. Clowse MEB, Scheuerle AE, Chambers C, Afzali A, Kimball $\mathrm{AB}$, Cush JJ, et al. Pregnancy outcomes after exposure to certolizumab pegol: updated results from a pharmacovigilance safety database. Arthritis Rheumatol. 2018;70(9):1399-407.
163. Clowse ME, Förger F, Hwang C, Thorp J, Dolhain RJ, van Tubergen A, et al. Minimal to no transfer of certolizumab pegol into breast milk: results from CRADLE, a prospective, postmarketing, multicentre, pharmacokinetic study. Ann Rheum Dis. 2017;76(11):1890-6.

164. Rocha K, Piccinin MC, Kalache LF, Reichert-Faria A, Silva-deCastro CC. Pregnancy during ustekinumab treatment for severe psoriasis. Dermatology. 2015;231(2):103-4.

165. MotherToBaby. Ustekinumab (Stelara $\left.{ }^{\circledR}\right)$ Fact Sheet. 2019. https://mothertobaby.org/fact-sheets/ustekinumab-pregnancy/ pdf/. Accessed 27 Nov 2020.

166. Meroni M, Generali E, Guidelli G, et al. THU0319 overall safety of 7-week secukinumab exposure during pregnancy in women with psoriatic arthritis. Annals Rheum Dis. 2018;77:377-8.

167. Warren RB, Reich K, Langley RG, Strober B, Gladman D, Deodhar A, et al. Secukinumab in pregnancy: outcomes in psoriasis, psoriatic arthritis and ankylosing spondylitis from the global safety database. Br J Dermatol. 2018;179(5):1205-7.

168. Deodhar A, Mease PJ, McInnes IB, Baraliakos X, Reich K, Blauvelt A, et al. Long-term safety of secukinumab in patients with moderate-to-severe plaque psoriasis, psoriatic arthritis, and ankylosing spondylitis: integrated pooled clinical trial and postmarketing surveillance data. Arthritis Res Ther. 2019;21(1):111.

169. Golbari NM, Basehore BM, Zito PM. Brodalumab. In: StatPearls. Treasure Island (FL): StatPearls Publishing; 2020.

170. Rademaker M, Agnew K, Andrews M, Armour K, Baker C, Foley $\mathrm{P}$, et al. Psoriasis in those planning a family, pregnant or breastfeeding. The Australasian Psoriasis Collaboration. Australas J Dermatol. 2018;59(2):86-100.

171. Pangallo R. Ixekizumab and pregnancy outcome. J Am Acad Dermatol. 2017;76(6):AB419.

172. Abrouk M, Beroukhim K, Nakamura M, Zhu TH, Farahnik B, Singh R, et al. Considerations on biologic agents in psoriasis with the new pregnancy lactation labeling rule. Int J Womens Dermatol. 2016;2(2):62-4.

173. Pouplard C, Brenaut E, Horreau C, Barnetche T, Misery L, Richard MA, et al. Risk of cancer in psoriasis: a systematic review and meta-analysis of epidemiological studies. J Eur Acad Dermatol Venereol. 2013;27(Suppl 3):36-46.

174. Lee MS, Lin RY, Chang YT, Lai MS. The risk of developing nonmelanoma skin cancer, lymphoma and melanoma in patients with psoriasis in Taiwan: a 10-year, population-based cohort study. Int J Dermatol. 2012;51(12):1454-60.

175. Gelfand JM, Shin DB, Neimann AL, Wang X, Margolis DJ, Troxel AB. The risk of lymphoma in patients with psoriasis. $\mathrm{J}$ Invest Dermatol. 2006;126(10):2194-201.

176. Brauchli YB, Jick SS, Miret M, Meier CR. Psoriasis and risk of incident cancer: an inception cohort study with a nested casecontrol analysis. J Invest Dermatol. 2009;129(11):2604-12.

177. Chiesa Fuxench ZC, Shin DB, Ogdie Beatty A, Gelfand JM. The risk of cancer in patients with psoriasis: a population-based cohort study in the health improvement network. JAMA Dermatol. 2016;152(3):282-90.

178. Tracey D, Klareskog L, Sasso EH, Salfeld JG, Tak PP. Tumor necrosis factor antagonist mechanisms of action: a comprehensive review. Pharmacol Ther. 2008;117(2):244-79.

179. Askling J, Fahrbach K, Nordstrom B, Ross S, Schmid CH, Symmons D. Cancer risk with tumor necrosis factor alpha (TNF) inhibitors: meta-analysis of randomized controlled trials of adalimumab, etanercept, and infliximab using patient level data. Pharmacoepidemiol Drug Saf. 2011;20(2):119-30.

180. Dommasch ED, Abuabara K, Shin DB, Nguyen J, Troxel AB, Gelfand JM. The risk of infection and malignancy with tumor necrosis factor antagonists in adults with psoriatic disease: a systematic review and meta-analysis of randomized controlled trials. J Am Acad Dermatol. 2011;64(6):1035-50. 
181. Mariette X, Matucci-Cerinic M, Pavelka K, Taylor P, van Vollenhoven R, Heatley R, et al. Malignancies associated with tumour necrosis factor inhibitors in registries and prospective observational studies: a systematic review and meta-analysis. Ann Rheum Dis. 2011;70(11):1895-904.

182. Asgari MM, Ray GT, Geier JL, Quesenberry CP. Malignancy rates in a large cohort of patients with systemically treated psoriasis in a managed care population. J Am Acad Dermatol. 2017;76(4):632-8.

183. Lopez-Olivo MA, Tayar JH, Martinez-Lopez JA, Pollono EN, Cueto JP, Gonzales-Crespo MR, et al. Risk of malignancies in patients with rheumatoid arthritis treated with biologic therapy: a meta-analysis. JAMA. 2012;308(9):898-908.

184. Waljee AK, Higgins PDR, Jensen CB, Villumsen M, CohenMekelburg SA, Wallace BI, et al. Anti-tumour necrosis factor- $\alpha$ therapy and recurrent or new primary cancers in patients with inflammatory bowel disease, rheumatoid arthritis, or psoriasis and previous cancer in Denmark: a nationwide, population-based cohort study. Lancet Gastroenterol Hepatol. 2020;5(3):276-84.

185. Strober B, Leonardi C, Papp KA, Mrowietz U, Ohtsuki M, Bissonnette R, et al. Short- and long-term safety outcomes with ixekizumab from 7 clinical trials in psoriasis: etanercept comparisons and integrated data. J Am Acad Dermatol. 2017;76(3):432-40.

186. Gottlieb A, Lebwohl M, Liu C, Israel RJ, Jacobson A. Malignancy rates in brodalumab clinical studies for psoriasis. Am J Clin Dermatol. 2020;21(3):421-30.

187. Gordon KB, Papp KA, Langley RG, Ho V, Kimball AB, Guzzo $\mathrm{C}$, et al. Long-term safety experience of ustekinumab in patients with moderate to severe psoriasis (Part II of II): results from analyses of infections and malignancy from pooled phase II and III clinical trials. J Am Acad Dermatol. 2012;66(5):742-51.

188. Bachelez H, Gordon K, Blauvelt A, Wu J, Sinvhal R, Photowala $\mathrm{H}$, et al. Short- and long-term safety of risankizumab in patients with moderate to-severe psoriasis: an integrated analysis. J Eur Acad Dermatol Venereol. 2019;37-8.

189. Yuen KS, Ye ZW, Fung SY, Chan CP, Jin DY. SARS-CoV-2 and COVID-19: the most important research questions. Cell Biosci. 2020;10:40.

190. Centers for Disease Control and Prevention. National Center for Health Statistics. Daily updates of totals by week and state: provisional death counts for coronavirus disease 2019 (COVID19). 2020. https://www.cdc.gov/nchs/nvss/vsrr/covid19/index. htm. Accessed 10 Oct 2020.

191. Polack FP, Thomas SJ, Kitchin N, Absalon J, Gurtman A, Lockhart S, et al. Safety and efficacy of the BNT162b2 mRNA Covid19 vaccine. N Engl J Med. 2020;383(27):2603-15.

192. Syed MN, Shah M, Shin DB, Wan MT, Winthrop KL, Gelfand JM. Effect of anti-tumor necrosis factor therapy on the risk of respiratory tract infections and related symptoms in patients with psoriasis - a meta-estimate of pivotal phase 3 trials relevant to decision-making during the COVID-19 pandemic. J Am Acad Dermatol. 2021;84(1):161-3. https://doi.org/10.1016/j.jaad. 2020.08.095.

193. Wan MT, Shin DB, Winthrop KL, Gelfand JM. The risk of respiratory tract infections and symptoms in psoriasis patients treated with interleukin 17 pathway-inhibiting biologics: a meta-estimate of pivotal trials relevant to decision making during the COVID19 pandemic. J Am Acad Dermatol. 2020;83(2):677-9.

194. Syed MN, Shin DB, Wan MT, Winthrop KL, Gelfand JM. The risk of respiratory tract infections in patients with psoriasis treated with interleukin 23 pathway-inhibiting biologics: a metaestimate of pivotal trials relevant to decision making during the COVID-19 pandemic. J Am Acad Dermatol. 2020;83(5):1523-6.
195. Ricardo JW, Lipner SR. Considerations for safety in the use of systemic medications for psoriasis and atopic dermatitis during the COVID-19 pandemic. Dermatol Ther. 2020;27:e13687.

196. Lebwohl M, Rivera-Oyola R, Murrell DF. Should biologics for psoriasis be interrupted in the era of COVID-19? J Am Acad Dermatol. 2020;82(5):1217-8.

197. Rivera-Oyola R, Koschitzky M, Printy R, Liu S, Stanger R, Golant AK, et al. Dermatologic findings in 2 patients with COVID-19. JAAD Case Rep. 2020;6(6):537-9.

198. Conforti C, Giuffrida R, Dianzani C, Di Meo N, Zalaudek I. COVID-19 and psoriasis: Is it time to limit treatment with immunosuppressants? A call for action. Dermatol Ther. 2020;11:e13298.

199. Brownstone ND, Thibodeaux QG, Reddy VD, Myers BA, Chan SY, Bhutani T, et al. Novel Coronavirus Disease (COVID19) and biologic therapy for psoriasis: successful recovery in two patients after infection with severe acute respiratory syndrome coronavirus 2 (SARS-CoV-2). Dermatol Ther (Heidelb). 2020;10(4):881-5.

200. Kalb RE, Fiorentino DF, Lebwohl MG, Toole J, Poulin Y, Cohen $\mathrm{AD}$, et al. Risk of serious infection with biologic and systemic treatment of psoriasis: results from the psoriasis longitudinal assessment and registry (PSOLAR). JAMA Dermatol. 2015;151(9):961-9.

201. Yiu ZZN, Smith CH, Ashcroft DM, Lunt M, Walton S, Murphy $\mathrm{R}$, et al. Risk of serious infection in patients with psoriasis receiving biologic therapies: a prospective cohort study from the british association of dermatologists biologic interventions register (BADBIR). J Invest Dermatol. 2018;138(3):534-41.

202. Gottlieb AB, Blauvelt A, Thaçi D, Leonardi CL, Poulin Y, Drew $\mathrm{J}$, et al. Certolizumab pegol for the treatment of chronic plaque psoriasis: results through 48 weeks from 2 phase 3 , multicenter, randomized, double-blinded, placebo-controlled studies (CIMPASI-1 and CIMPASI-2). J Am Acad Dermatol. 2018;79(2):30214.e6.

203. Lebwohl M, Blauvelt A, Paul C, Sofen H, Węgłowska J, Piguet $\mathrm{V}$, et al. Certolizumab pegol for the treatment of chronic plaque psoriasis: Results through 48 weeks of a phase 3, multicenter, randomized, double-blind, etanercept- and placebo-controlled study (CIMPACT). J Am Acad Dermatol. 2018;79(2):266-76.e5.

204. Pacha O, Sallman MA, Evans SE. COVID-19: a case for inhibiting IL-17? Nat Rev Immunol. 2020;20(6):345-6.

205. Megna M, Napolitano M, Fabbrocini G. May IL-17 have a role in COVID-19 infection? Med Hypotheses. 2020;140:109749.

206. Price KN, Frew JW, Hsiao JL, Shi VY. COVID-19 and immunomodulator/immunosuppressant use in dermatology. J Am Acad Dermatol. 2020;82(5):e173-5.

207. Kearns DG, Uppal S, Chat VS, Wu JJ. Use of systemic therapies for psoriasis in the COVID-19 era. J Dermatolog Treat. 2020;27:1-14.

208. Chat VS, Uppal SK, Kearns DG, Wu JJ. Clinical management of psoriasis patients during the COVID-19 pandemic. J Dermatolog Treat. 2020;22:1-2.

209. ClinicalTrials.gov. A study to assess if mirikizumab is effective and safe compared to secukinumab and placebo in moderate to severe plaque psoriasis (OASIS-2). 2020.XXX Accessed 2 Oct 2020.

210. ClinicalTrials.gov. A study to evaluate the efficacy and safety of mirikizumab (LY3074828) in participants with moderate-tosevere plaque psoriasis (OASIS-1). 2020. XXX. Accessed 2 Oct 2020.

211. Eli Lilly and Company. Lilly's Mirikizumab Superior to Cosentyx ${ }^{\circledR}$ (secukinumab) in a Phase 3 Study for Patients with Moderate to Severe Plaque Psoriasis. 2020. https://investor.lilly.com/ news-releases/news-release-details/lillys-mirikizumab-super ior-cosentyxr-secukinumab-phase-3-study. Accessed 3 Oct 2020. 
212. Chambers JD, Lai RC, Margaretos NM, Panzer AD, Cohen JT, Neumann PJ. Coverage for biosimilars vs. reference products among US commercial health plans. JAMA. 2020;323(19):1972-3.

213. Griffiths CEM, Thaçi D, Gerdes S, Arenberger P, Pulka G, Kingo $\mathrm{K}$, et al. The EGALITY study: a confirmatory, randomized, double-blind study comparing the efficacy, safety and immunogenicity of GP2015, a proposed etanercept biosimilar, vs. the originator product in patients with moderate-to-severe chronic plaque-type psoriasis. Br J Dermatol. 2017;176(4):928-38.

214. Jørgensen KK, Olsen IC, Goll GL, Lorentzen M, Bolstad N, Haavardsholm EA, et al. Switching from originator infliximab to biosimilar CT-P13 compared with maintained treatment with originator infliximab (NOR-SWITCH): a 52-week, randomised, double-blind, non-inferiority trial. Lancet. 2017;389(10086):2304-16.
215. Papp K, Bachelez H, Costanzo A, Foley P, Gooderham M, Kaur $\mathrm{P}$, et al. Clinical similarity of biosimilar ABP 501 to adalimumab in the treatment of patients with moderate to severe plaque psoriasis: a randomized, double-blind, multicenter, phase III study. J Am Acad Dermatol. 2017;76(6):1093-102.

216. Liu LF, Chen JS, Gu J, Xu JH, Jin HZ, Pang XW, et al. Etanercept biosimilar (recombinant human tumor necrosis factor- $\alpha$ receptor II: IgG Fc fusion protein) and methotrexate combination therapy in Chinese patients with moderate-to-severe plaque psoriasis: a multicentre, randomized, double-blind, placebo-controlled trial. Arch Dermatol Res. 2020;312(6):437-45. 